\title{
Lightning characteristics observed by a VLF/LF lightning detection network (LINET) in Brazil, Australia, Africa and Germany
}

\author{
H. Höller ${ }^{1}$, H.-D. Betz ${ }^{2}$, K. Schmidt ${ }^{3}{ }^{*}$, R. V. Calheiros ${ }^{4}$, P. May ${ }^{5}$, E. Houngninou ${ }^{6}$, and G. Scialom ${ }^{7}$ \\ ${ }^{1}$ Deutsches Zentrum für Luft- und Raumfahrt, Institut für Physik der Atmosphäre, Oberpfaffenhofen, Germany \\ ${ }^{2}$ Physics Department, University of Munich, Germany \\ ${ }^{3}$ nowcast GmbH, Munich, Germany \\ ${ }^{4}$ Instituto de Pesquisas Meteorológicas/Universidade Estadual Paulista, Bauru, Brazil \\ ${ }^{5}$ Centre for Australian Weather and Climate Research, Melbourne, Australia \\ ${ }^{6}$ University Abomey Calavi, Cotonou, Benin \\ ${ }^{7}$ Centre d'étude des Environnements Terrestre et Planétaires, Vélizy, France \\ *now at: Deutsches Zentrum für Luft- und Raumfahrt, Institut für Physik der Atmosphäre, Oberpfaffenhofen, Germany
}

Received: 24 January 2009 - Published in Atmos. Chem. Phys. Discuss.: 6 March 2009

Revised: 14 July 2009 - Accepted: 27 August 2009 - Published: 20 October 2009

\begin{abstract}
This paper describes lightning characteristics as obtained in four sets of lightning measurements during recent field campaigns in different parts of the world from mid-latitudes to the tropics by the novel VLF/LF (very low frequency/low frequency) lightning detection network (LINET). The paper gives a general overview on the approach, and a synopsis of the statistical results for the observation periods as a whole and for one special day in each region. The focus is on the characteristics of lightning which can specifically be observed by this system like intra-cloud and cloud-to-ground stroke statistics, vertical distributions of intra-cloud strokes or peak current distributions. Some conclusions regarding lightning produced $\mathrm{NO}_{\mathrm{x}}$ are also presented as this was one of the aims of the tropical field campaigns TROCCINOX (Tropical Convection, Cirrus and Nitrogen Oxides Experiment) and TroCCiBras (Tropical Convection and Cirrus Experiment Brazil) in Brazil during January/February 2005, SCOUTO3 (Stratospheric-Climate Links with Emphasis on the Upper Troposphere and Lower Stratosphere) and TWP-ICE (Tropical Warm Pool-International Cloud Experiment) during November/December 2005 and January/February 2006, respectively, in the Darwin area in N-Australia, and of AMMA (African Monsoon Multidisciplinary Analyses) in W-Africa during June-November 2006.
\end{abstract}

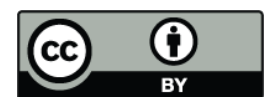

Correspondence to: H. Höller (hartmut.hoeller@dlr.de)
Regional and temporal characteristics of lightning are found to be dependent on orographic effects (e.g. SGermany, Brazil, Benin), land-sea breeze circulations (NAustralia) and especially the evolution of the monsoons (Benin, N-Australia). Large intra-seasonal variability in lightning occurrence was found for the Australian monsoon between the strong convection during build-up and break phases and the weak active monsoon phase with only minor lightning activity. Total daily lightning stroke rates can be of comparable intensity in all regions with the heaviest events found in Germany and N-Australia. The frequency of occurrence of such days was by far the largest in N-Australia. In accordance with radar observed storm structures, the intracloud stroke mean emission heights were found distinctly different in Germany $(8 \mathrm{~km}$ ) as compared to the tropics (up to $12 \mathrm{~km}$ in N-Australia). The fraction of intra-cloud strokes (compared to all strokes) was found to be relatively high in Brazil and Australia (0.83 and 0.82, respectively) as compared to Benin and Germany (0.64 and 0.69, respectively).

Using stroke peak currents and vertical location information, lightning $\mathrm{NO}_{\mathrm{x}}\left(\mathrm{LNO}_{\mathrm{x}}\right)$ production under defined standard conditions can be compared for the different areas of observation. $\mathrm{LNO}_{\mathrm{x}}$ production per standard stroke was found to be most efficient for the N-Australian and SGerman thunderstorms whereas the yield from Brazilian and W-African strokes was nearly $40 \%$ less. On the other hand, the main NO contribution in Brazil was from intra-cloud (IC) strokes whereas in Benin it was due to cloud-to-ground (CG)

Published by Copernicus Publications on behalf of the European Geosciences Union. 
components. For the German and Australian strokes both stroke types contributed similar amounts to the total NO outcome.

\section{Introduction}

In recent years lightning has come into the focus of scientific interest not only because it is one form of severe weather associated with thunderstorms but also because of its role in atmospheric chemistry. Lightning is an important natural source of nitrogen oxides $\left(\mathrm{NO}_{\mathrm{x}}=\mathrm{NO}+\mathrm{NO}_{2}\right)$ which is present throughout the troposphere. $\mathrm{NO}_{\mathrm{x}}$ concentration determines the ozone destruction and production rates (Crutzen, 1970) and directly influences the oxidation capacity of the atmosphere (WMO, 1995). But the global source strength of the lightning $\mathrm{NO}_{\mathrm{x}}\left(\mathrm{LNO}_{\mathrm{x}}\right)$ source is still rather uncertain even though much progress has been made during the last years. In a recent review Schumann and Huntrieser (2007) report the global annual nitrogen source from lightning in the range $5 \pm 3 \mathrm{Tg}(\mathrm{N}) \mathrm{a}^{-1}$ as the best estimate, mainly based on model fits to observational data. In the model approach as well as in the extrapolation methods based on flash parameters (e.g. Lawrence et al., 1995) the knowledge of these flash properties and their significance for $\mathrm{NO}_{\mathrm{x}}$ production is still poor. This includes the occurrence and $\mathrm{LNO}_{\mathrm{x}}$ productivity (specific and length-induced) of the different flash types (cloud-to-ground CG or intra-cloud IC) and components (leaders, return strokes, continuous currents etc.) in different regions of the world.

Knowledge on the global distribution of lightning has been increased a lot due to space-borne measurements. During a 5-year period from 1995 to 2000 optical observations of lightning were performed by the Optical Transient Detector (OTD) revealing the global average and the regional distribution of lightning (Christian et al., 2003). It was found that the average global flash rate amounts to $44 \pm 5$ flashes per second. This includes both, intra-cloud and cloud-to-ground flashes which cannot be discriminated by the sensor. Land to ocean differences in flash occurrence are very pronounced. The mean annual land to ocean flash ratio is 10:1. Nearly $80 \%$ of the annual lightning occurs in the wider tropical regions between $30^{\circ} \mathrm{S}$ and $30^{\circ} \mathrm{N}$. On the other hand, Northern Hemisphere continental summer convection, especially over $\mathrm{N}$-America, contributes a significant part to the global flash rate.

The above mentioned regions of generally enhanced lightning occurrence have been target areas in international field experiments focusing on lightning-produced $\mathrm{NO}_{\mathrm{x}}$. During June and July 1996 the Stratospheric-Tropospheric Experiment: Radiation, Aerosols, and Ozone (STERAO) convective field study was conducted in north-eastern Colorado (Dye et al., 2000). Lightning was measured by the ONERA three-dimensional (3-D) lightning interferometer and the Na- tional Lightning Detection Network (NLDN). Results from a case study indicate that intra-cloud lightning can play a dominant role in $\mathrm{NO}_{\mathrm{x}}$ production.

Extensive $\mathrm{NO}_{\mathrm{x}}$ measurements in thunderstorms have been performed in central Europe during the DLR-experiment LINOX (Lightning produced $\mathrm{NO}_{\mathrm{x}}$ ) in July 1996 (Höller et al., 1999; Huntrieser et al., 1998) and the European Commission sponsored EULINOX (European Lightning Nitrogen Oxides Project) field campaign during July 1998 (Höller and Schumann, 2000; Huntrieser et al., 2002). During both campaigns lightning measurements from the Siemens-LPATS (Lightning Positioning and Tracking System) network were available. Additionally, during EULINOX the ONERA interferometer did provide data on VHF emissions from lightning.

From LINOX and EULINOX airborne chemical measurements during aircraft penetrations of thunderstorm anvils it was found that the fraction of $\mathrm{LNO}_{\mathrm{x}}$ to total anvil $\mathrm{NO}_{\mathrm{x}}$ (ground emissions being a major $\mathrm{NO}_{\mathrm{x}}$ source) increases with thunderstorm size and could contribute up to $80 \%$ (LINOX) or $70 \%$ on average during EULINOX in the observed storms. EULINOX lightning measurements gave indication that IC flashes might be efficient $\mathrm{NO}_{\mathrm{x}}$ producers.

In the tropics of northern Australia lightning-produced $\mathrm{NO}_{\mathrm{x}}$ was investigated within the framework of the 'Biomass Burning and Lightning Experiment - Phase C (BIBLE-C) airborne campaign during December 2000 (Koike et al., 2007). Plumes of upper tropospheric $\mathrm{NO}_{\mathrm{x}}$ were measured and their origin could be related to lightning observations from the Australian GPATS (Global Positioning and Tracking System) network. Due to the small number of lightning sensors and the far distance of the airborne measurements from the sensors, large uncertainties were still present in the assessment of lightning characteristics and $\mathrm{LNO}_{\mathrm{x}}$ production rates.

The EU-funded TROCCINOX (Tropical Convection, Cirrus and Nitrogen Oxides Experiment) campaign was performed during the two rainy seasons of January/February/March 2004 and January/February 2005 in the state of São Paulo/Brazil (Schumann and Huntrieser, 2007 and see the special issue on TROCCINOX in this journal). A comparison of airborne chemical measurements, spaceborne observations from the OTD (Optical Transient Detector) and LIS (Lightning Imaging Sensor) lightning record statistics (Christian et al., 2003; Mach et al., 2007), and LINET lightning detection during the second field campaign in 2005 revealed scaling factors relating the local lightning observations to the annual global lightning $\mathrm{NO}_{\mathrm{x}}$ production rate (Huntrieser et al., 2008) which could be assessed to amount from $1.6 \mathrm{Tg}(\mathrm{N}) \mathrm{a}^{-1}$ for deep convection of tropical type up to $3.1 \mathrm{Tg}(\mathrm{N}) \mathrm{a}^{-1}$ for a sub-tropical thunderstorm assumed as globally representative storm prototypes.

SCOUT-O3 (Stratospheric-Climate Links with Emphasis on the Upper Troposphere and Lower Stratosphere, sponsored by the EC, for general information see http://www. 
ozone-sec.ch.cam.ac.uk/scout_o3/) performed a tropical field campaign out of Darwin/Australia in co-operation with a NERC funded ACTIVE (Aerosol and chemical transport in tropical convection) campaign during November/December 2005 during the monsoon build-up phase (Brunner et al., 2009; Vaughan et al., 2008). Lightning $\mathrm{NO}_{\mathrm{x}}$ produced by deep tropical thunderstorms was among the campaign objectives. Convective processes during the established monsoon were investigated during January/February 2006 within the TWP-ICE project (Tropical Warm Pool - International Cloud Experiment; May et al., 2008a, b; Frederick and Schumacher, 2008; for general information see http://www. bom.gov.au/bmrc/wefor/research/twpice.htm). Recently, the AMMA (African Monsoon Multidisciplinary Analyses; Redelsperger et al., 2006; Janicot et al., 2008) special observation period (SOP, May-September 2006) was partly focusing on lightning $\mathrm{NO}_{\mathrm{x}}$ produced from convective complexes over West-Africa. During all three field studies (TROCCINOX, SCOUT-O3, and AMMA) airborne chemical measurements were performed by the DLR-Falcon and the Russian Geophysica aircraft.

During recent years a new VLF/LF (very low frequency/low frequency) lightning observation technology has been developed (Betz et al., 2004) at the University of Munich (LMU). It utilizes magnetic field measurements at easily deployable field stations which are operated as a network. Time stamps for the observed VLF signals are obtained from GPS receivers at each station and thus the analysis of stroke locations can be done by a time of arrival (TOA) method. Using newly developed hardware and software components, the system is able to provide not only information of the horizontal (latitude-longitude) position of the observed lightning events but also of its vertical position. For distances not exceeding about $120 \mathrm{~km}$ from the closest station cloud to ground (CG) strokes can be discriminated from intra-cloud (IC) strokes. Presently, an operational network of around 90 sensors covers large parts of Europe (Betz et al., 2008 b). A 6-station network was operated by DLR during the tropical campaigns mentioned above (see Fig. 1). Moreover, the network was deployed during June-August 2005 around the DLR site in Southern Germany thus, additionally to the operational network of LMU, contributing to a very dense local network.

The detection efficiency of the network depends on the distance of a stroke to the sensors as well as on the internal detection threshold of each sensor determined by technical aspects of the sensors as well as by software settings which were adjusted in order to avoid too many noise sources from being recorded. It was kept constant for all stations during all experiments thus ensuring the comparability of the results from all experiments. For a typical network configuration used here (a central station and five remote stations at around $100 \mathrm{~km}$ radial distance from it) the minimum detectable signal is in the range $1-2 \mathrm{kA}$. This implies that within the very inner network area most of the ground flashes are detected

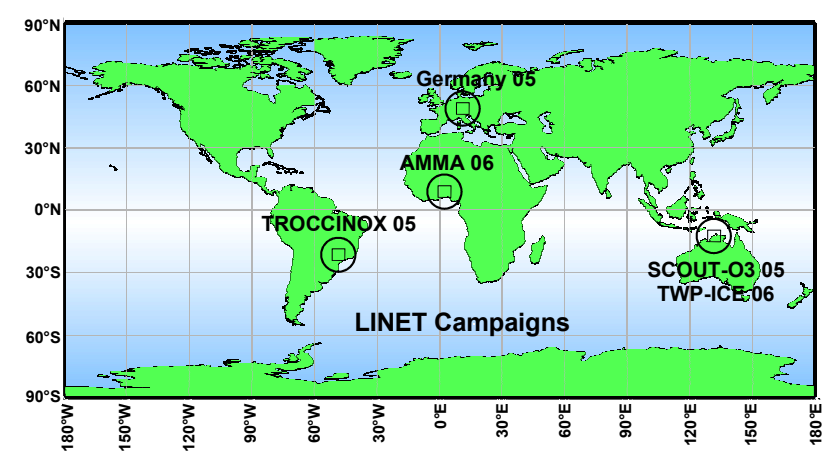

Fig. 1. LINET deployments during the different field campaigns in 2005 and 2006.

whereas some cloud flashes might even have lower amplitudes and thus will not be recorded. This sensitivity decreases gradually with distance of a stroke location from the network center resulting in a typical detection threshold of $10 \mathrm{kA}$ in a radial distance of around $300 \mathrm{~km}$.

The charge transfer in a thunderstorm is accomplished by many processes like leaders, strokes or continuous currents. LINET measures the VLF/LF emissions of impulsive stroke processes happening within the clouds or making connection to the ground. The VLF/LF events detected by LINET arise from a discharge process leading to relatively large currents between areas of opposite charge flowing over distances (larger than a few $100 \mathrm{~m}$ ) larger than those typically involved in the stepwise propagations of leader processes. Therefore, LINET detects a totally different part of a discharge as compared to VHF systems. The VLF/LF events seen by LINET are thought to arise from return strokes of ground flashes, from preliminary breakdown processes, from K-processes (or recoil streamers) occurring during IC-activity of ground flashes as well as for pure cloud flashes. Another identified group of VLF/LF emissions in the cloud is represented by the so called narrow bipolar events (NBE) which is identified as a strong, well defined pulse (see Betz et al., 2008). As both types of VLF/LF-events (the cloud and the ground events) are due to stronger currents flowing in relatively long channels, the term "stroke" is used in the following as synonymous for "VLF/LF event". In the case of CG strokes one can assume that the VLF/LF emissions arise from the ground strike point. For IC strokes we cannot tell at present which point along a lightning channel corresponds to the VLF/LF source location in 3-D. As the horizontal field components of the magnetic field are measured by LINET we expect that the vertical channel components are responsible for the measured effects.

LINET provides vertical source information for each event such that IC and CG events are discriminated. One or several VLF/LF sources can be attributed to the complete flash. A flash may consist of a series of IC and CG events in arbitrary order. If one of those components is of type CG 
Table 1. The different areas of analysis used in Brazil.

\begin{tabular}{llll}
\hline Area & Description & Size & \\
\hline A & Overall area of analysis & $6^{\circ} \times 6^{\circ}$ & \\
& & Longitude: & $-46.0^{\circ}$ to $-52.0^{\circ}$ \\
& Latitude: & $-19.0^{\circ}$ to $-25.0^{\circ}$ \\
D & CG-IC discrimination area & $120 \mathrm{~km}$ around stations & \\
I & Inner area of analysis & $1.6^{\circ} \times 1.6^{\circ}$ & $-48.3^{\circ}$ to $-49.9^{\circ}$ \\
& & Longitude: & $-21.4^{\circ}$ to $-23.0^{\circ}$ \\
\hline
\end{tabular}

(VLF/LF source at ground level) the flash is called a ground flash (termed CG for simplicity). In case of a pure succession of IC events the flash is called a cloud flash (termed IC for simplicity). In this context the definition of a flash is somewhat arbitrary and may be done by grouping all VLF/LF events happening within a prescribed time interval and distance from each other (e.g. $1 \mathrm{~s}$ and $10 \mathrm{~km})$. But it is not clear a priori how to fix these parameters and if they apply to all possible thunderstorm situations. This is one reason why we prefer to use the original strokes in the context of the present paper and regard the grouping as an issue to be followed in a separate study which, on the other hand, may be very useful for improving general understanding of discharge processes. Another reason is the loss of information when simply counting flashes instead of the contributing components which give better information of the intensity of the discharge. The number and strength of these VLF/LF component strokes is some kind of measure of the electric power of a thunderstorm what is ultimately what we want to know and to compare for the different regions. Especially when comparing data from the same measuring system for different regions there is no need to look at flashes as long as we do not intend to compare to outputs from other lightning detection sensors providing different properties of lighting (like VHF or optical detection). In the latter case a flash definition might be helpful as common base for interpretation. Also the $\mathrm{NO}_{\mathrm{x}}$ production aspect favours the use of strokes instead of flashes as each stroke is assumed to contribute separately to the total $\mathrm{NO}_{\mathrm{x}}$ production of a flash.

LINET detects and locates an IC stroke in exactly the same way as it detects and locates CG strokes. In fact, the measured signals are very similar for the two types of strokes. The polarity depends on the charge distribution, i.e. whether negative charge is lowered or raised during the discharge (just as for CG) and not whether the leader charge is positive or negative. Of course, these arguments hold only for vertical cloud discharges. It is assumed that there are dominantly vertical discharges. LINET determines the stroke polarity from the peaks of the observed wave forms. This and the questions raised before have been discussed in detail in a recent paper by Betz et al. (2007).
Having operated the same kind of lightning detection network in different regions of the world now allows for comparison of the lightning characteristics in these areas based on the identical ground-based system. The present paper presents the configuration of the networks in the different areas from tropical regions to mid-latitudes and provides a first overview of the different lightning characteristics. Some implications for lightning $\mathrm{NO}_{\mathrm{x}}$ production are discussed.

\section{Characteristics of the network deployments and light- ning occurrence}

\subsection{The TROCCINOX network in Brazil}

During January 2005 a 6-station LINET network was set up in the state of São Paulo/Brazil. The deployment was performed in collaboration with a team of IPMet/UNESP (Instituto de Pesquisas Meteorológicas/Universidade Estadual Paulista) at different locations around the Bauru radar (see Fig. 2). An optimum spacing of the stations of around $100 \mathrm{~km}$ network baseline could be realized. Four of the stations had internet connection, so online control of the measurements was possible. The system was only available during the second TROCCINOX field campaign in Brazil and was in operation from 21 January till 28 February 2005 thus covering only the final part of the convective season. The stations were located at Bauru, Botocatu, Araraquara, Novo Horizonte, Marilia and Ourinhos. The locations of the stations prescribe an inner analysis area (I) where best data quality can be expected. It was chosen as a box of $1.6 \times 1.6$ degree size for all experimental areas investigated in this study. In São Paulo state it was located from $-48.3^{\circ}$ to $-49.9^{\circ}$ in longitude and from $-21.4^{\circ}$ to $-23.0^{\circ}$ in latitude (see Table 1). The TROCCINOX and TroCCiBras aircraft were based at Araçatuba to the NW of the LINET grid. The flight planning was such that the LINET and radar area was a target region for the local thunderstorm flight missions.

Figure 3a shows the sensitivity of the network with regard to the stroke peak power (amplitude). It is based on all measurements during the observational period and indicates the areas inside which events of the indicated peak power have 


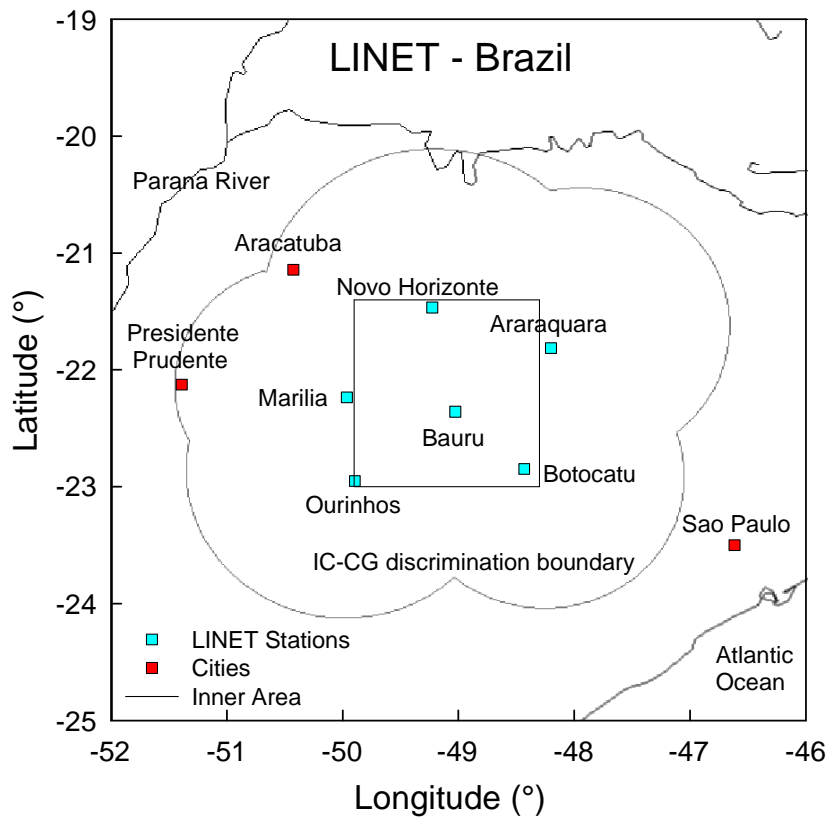

Fig. 2. LINET deployment during TROCCINOX/TroCCiBras in January/February 2005 in the State of São Paulo around the IPMet radar site in Bauru (central station). IC-CG discrimination can be performed within $120 \mathrm{~km}$ radial distance around each station as indicated by the circular segments circumscribing the discrimination area (D). Data quality is best in the inner analysis square area (I). IPMet operates another weather radar at Presidente Prudente. The aircraft were based at Araçatuba.

been measured. Detection of $2 \mathrm{kA}$ strokes is confined to the "inner" area (I) approximately bounded by the position of the stations. The patterns are more or less circular shaped with sensitivity decreasing with range. In the following we confine the maximum range of analysis (A) to grid boxes of $6 \times 6$ degrees of longitude and latitude for the tropical regions. This corresponds to roughly $660 \times 660 \mathrm{~km}^{2}$. We note from Fig. 3a that inside this area stroke amplitudes larger than $10 \mathrm{kA}$ will be detected by the system when happening anywhere in the box. Amplitudes smaller than $10 \mathrm{kA}$ are not detected everywhere in area (A) but their detection efficiency increases towards the center. Thus a $10 \mathrm{kA}$ lower amplitude limit is suitable for doing regional statistics of lightning occurrence within the box area (A).

Figure $3 b$ shows a summary of the regional stroke distribution derived from all stroke measurements with amplitudes larger than $10 \mathrm{kA}$. For the total period and the large area A (small inner area I) these are $27 \%(11 \%)$ of all strokes observed. We note a higher lightning occurrence in the eastern part of São Paulo state which is generally the more elevated part of the state, with the highest ridges $(1200 \mathrm{~m})$ close to the Atlantic coast. The western part shows less lightning activity with a minimum along the Paraná river basin. A pronounced maximum is present in the São Paulo metropolitan area. Even if the underlying LINET data base extends only to slightly more than one month, this general pattern is in qualitative good agreement with the average annual distribution of ground flash occurrence derived from the Brazilian RINDAT network for the period 1999-2004 (Pinto et al., 2007). Pinto et al. (2007) state that lightning characteristics is determined by orography, urban heat island and land-sea breeze effects especially when interacting with cold fronts. The effects on lightning have been clearly demonstrated by Naccarato at al. (2003) for the urban area of São Paulo. An increase of CG flash rate of 60-100\% over the surrounding region was found.

The summertime convective activity in Brazil is generally characterized by the South American Monsoon System (SAMS) whose major components are the extended area of deep convection over the Amazon basin and the South Atlantic convergence zone (SACZ) which is an elongated convective band typically originating in the Amazon basin, extending toward southeast Brazil and protruding into the south-eastern subtropical Atlantic Ocean (Carvalho et al., 2004; Jones and Carvalho, 2002). The SE of Brazil, and in the context of the present paper, the state of São Paulo is not only prone to the varying activity of the SACZ but, due to its southern geographical location, also to its interaction with Rossby waves (Liebmann et al., 1999). These waves pass over the region with their associated cold fronts replacing the humid tropical air mass originating from the Amazon region by a cooler and dryer sub-tropical air mass from the south.

These variations are reflected by the variation of the lightning characteristics in the total experimental period is shown in Fig. 4. CG and IC signals can only be discriminated within the closer observation area of the network (discrimination area). This area is defined by a distance between the stroke location and the closest station of the network not exceeding $120 \mathrm{~km}$. Strokes outside of this area can only be located in $2-D$, i.e. no height information can be inferred here. Thus the total number of strokes in the overall region $(6 \times 6$ degrees) is larger than just the sum of the CG and IC numbers. For all CG and IC studies presented in the following, data analysis is further confined to the respective inner area (I) as the data quality is highest there. Thus, in Fig. 4 (as well as also in the time series plots for the other experimental areas) the CG and IC data show gaps for no-lightning days in the inner area. On the other hand, the time series plots include days where less than six stations were active, provided that the results were still reasonable. This is the case as long as the lightning activity is observed within the high-sensitivity part of the inner area in case of only 4 or 5 station operations. The number and the configuration of the active stations of the network is determining the pattern of sensitivity leading to a nonhomogeneous detection efficiency. A more careful data reduction has to be performed especially in case of stroke peak current analysis as will be presented in Sect. 3.2. Thus the highest data quality is obtained within the inner area in case of the complete network being operative with all 6 stations 

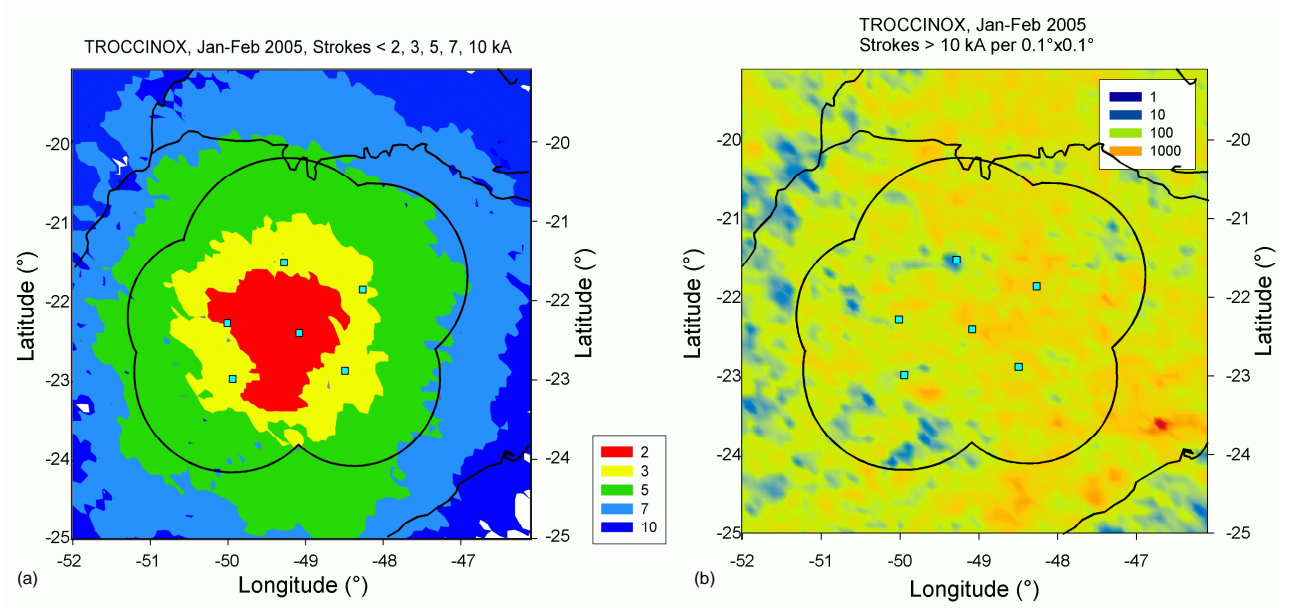

Fig. 3. (a) Detection area for strokes smaller than the indicated amplitude values and (b) stroke statistics for events exceeding $10 \mathrm{kA}$ in amplitude from all stroke types during all experimental days from the period 21 January till 28 February 2005 in Brazil.

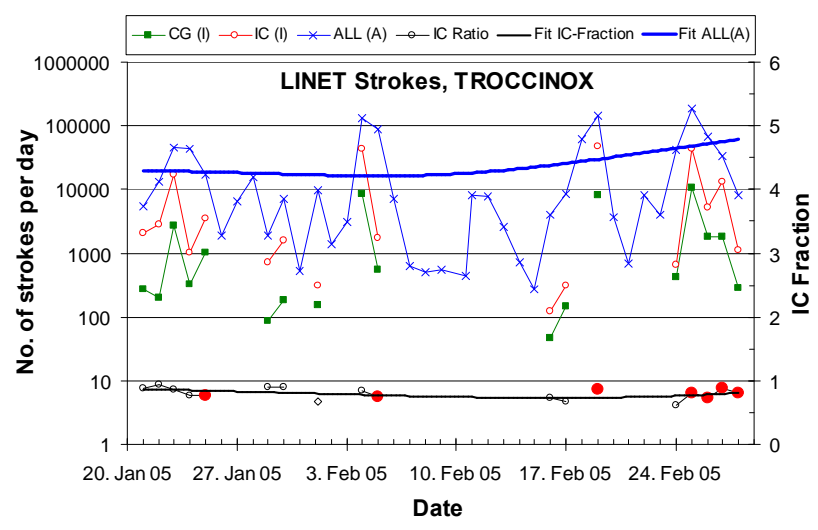

Fig. 4. Daily number of strokes during the experimental period in January and February 05 in Brazil as inferred from LINET measurements. CG and IC strokes from the inner area (I) are shown while the "ALL" data are observed within the wide box area (A). Red dots indicate the "core" data set with six stations being operative. 3rd order polynomial fits show long-term trends.

being active. These days ("core" data set) are indicated at the bottom of Fig. 4 by the red dots on the IC-fraction graph.

The area of detection for the "ALL" category is defined by the 6x6 degree grid shown in Fig. 2. Events outside of this area are not considered here for reasons of comparing approximately the same area size in each network configuration for the different continents. The total stroke numbers are shown in Fig. 4 for illustrating periods of activity which are happening in a larger region around the network and so indicate some kind of convective activity in the wider region.

From Fig. 4 it is noted that the overall lightning activity in the total area is subject to an oscillation of about 5-10 days. During 4 pronounced periods high lightning activity was found within the LINET area. During these periods the daily stroke numbers are well above the average activity which is approximated by a fitting 3rd order polynomial. There was a general trend of increased activity during the last phase of the observations. No lightning was observed in the inner area during periods of generally low activity. The total mean of the IC fraction, which is defined as the fraction of IC stroke number $\mathrm{N}_{I C}$ of the total stroke number $\mathrm{N}_{I C}+\mathrm{N}_{\mathrm{CG}}$

$\mathrm{F}_{\mathrm{IC}}=\mathrm{N}_{\mathrm{IC}} /\left(\mathrm{N}_{\mathrm{IC}}+\mathrm{N}_{\mathrm{CG}}\right)$,

amounts to 0.83 within the thunderstorm period derived from the core day events shown in Fig. 4 within the inner area (I). Thus it reflects the result obtained with maximum possible detection efficiency, not excluding the weak stroke part of the spectrum as it was done for the regional distribution shown in Fig. 3b.

In the following case study results will illustrate typical examples of lightning development and distribution. On 19 February 2005 the region was located at the southern fringes of the SACZ and deep convection developing the day before was still present during night and re-developed during the afternoon. This day was classified as in a transitional regime between sub-tropical and tropical air mass conditions by Huntrieser et al. (2008). Upper level winds (200 hPa) were rather strong due to the subtropical jet present over the region.

The daily lightning summary is shown in Fig. 5. The hourly stroke locations of CG, IC and UK (unknown identity) are shown in the horizontal projection while the vertical sections show projections of the IC heights. One can notice the night-time activity (blue colors) and the convection developing later during daytime. Distinct cells can be seen which are not highly organized. Due to the relatively high wind speeds aloft, the cells can be tracked for up to $2 \mathrm{~h}$ moving from SW to NE. The individual cell events can also be detected in the vertical. Fig. 5 shows all IC events regardless 


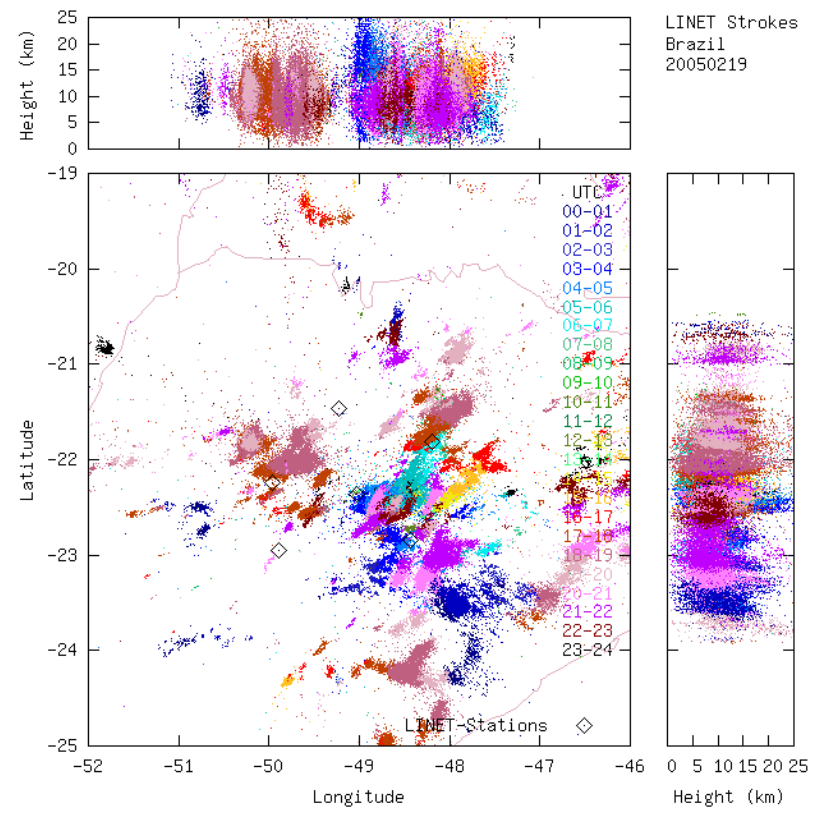

Fig. 5. Evolution of lightning activity measured by LINET on 19 February 2005. Stroke location for all types is shown in the Lat/Lon panel while the vertical sections show IC strokes only.

of the error in the vertical position. This causes some spread of the data points especially at cloud top.

The different sources of location errors of the pseudo 3-D technique used with the LINET system have been discussed in Betz et al. (2004). Primarily the technique has been targeted at discriminating IC and CG strokes rather than precise height mapping of IC emission events. On the other hand, the derived height information is well reflecting the bulk of the cloud structures as evidently shows up in the comparisons with the radar structures of storms as shown in the different examples in the following discussion for each of the experimental areas. Location errors which occasionally might e.g. lead to an overestimation of emission heights can arise from (1) statistical distributed GPS time errors, (2) site errors specific to the conditions around each station (like ground conductivity or orography), (3) complex pulse shapes or other reasons. In the framework of the TOA method used here the location errors can be expressed in terms of a minimized chisquared fitting procedure (Schmidt, 2007)

$\chi^{2}=\frac{1}{\sigma_{t}^{2}} \frac{1}{\mathrm{~N}-1} \sum_{i=1}^{\mathrm{N}-1}\left(d t_{i, i+1}-\frac{1}{v_{p}}\left(s_{i, s t}-s_{i+1, s t}\right)\right)^{2}$

where $\mathrm{N}$ is the number of stations recording the same event, $\sigma_{t}$ is the average GPS time error assumed equal at each of the stations, $d t_{i, j}$ is the time lag of a signal recorded at station $\mathrm{i}$ and station $\mathrm{j}, v_{p}$ is the propagation velocity of the signal and $s_{i, s t}$ is the distance (assumed as spherical segment on the earth's surface $s_{2-D}$ ) between the assumed stroke location and the ith station. An additional length scale $h$ is added in case of a radiation source at height $h$ rather than at the ground to form the 3-D distance $s_{3-\mathrm{D}}$

$s_{3-\mathrm{D}}=\sqrt{s_{3-\mathrm{D}}^{2}+h^{2}}$

which is used in the minimization procedure. The overall error of the complete localization procedure for an individual stroke can be defined as the semi-major axis of the $50 \%$ confidence ellipse around the optimum location found from the $\chi^{2}$ minimization. Examples of the horizontal and vertical measurement errors will be discussed along with the radar comparisons, e.g. Fig. 7.

The two thunderstorm periods are clearly to be seen from the time series shown in Fig. 6. The most intense peak intensifies at about 17:00 UTC when IC stroke numbers increase rapidly. The distribution of the ground strokes changes more smoothly with time but reflects the same thunderstorm events as do the IC strokes. The IC-fraction ranges most of the time around 0.9 thus indicating the dominant role of the IC events accounting for at least $90 \%$ of all strokes. This fraction might even be higher due to weaker IC-events undetected by the network due to sensitivity reasons. The fraction found is typical for all the data from the Brazilian storms (average $\mathrm{F}_{\mathrm{IC}}$ of 0.83 ) obtained during this study and is reflected in the overview shown in Fig. 4. In this specific case of 19 February 2005 , there is not much difference between the stroke characteristics in the total discrimination area (D) (as used in Figs. 5 and 6) and the inner area (I), except for total numbers due to the storm position. This is mainly due to the fact that all 6 stations were operative the whole day long and no recording gaps affect the computation of the stroke locations and the data analysis.

The LINET system was covering a region around the Bauru Doppler radar operated by IPMet/UNESP. The radar performed volume scans every $7.5 \mathrm{~min}$. During TROCCINOX/TroCCiBras in 2004 and 2005 the radar data were used for thunderstorm nowcasting and guidance for the airborne operations. As in all the regions under investigation, the LINET system was deployed around a radar site as radar information is essential for relating lightning and precipitation characteristics of convective storms. In the present study we focus on the lightning alone but present some examples of where lightning typically happens in relation to the radar detected precipitation. As an example for the Brazilian convection we present a case study from 4 February 2005 which was the "Golden Day" of the TROCCINOX-2 campaign due to a good coverage by coordinated measurements of all experimental systems, including airborne measurements within the radar area. Some description of this case has already been given in Huntrieser et al. (2008).

Figure 7 shows the radar - lightning comparison in a horizontal section at $6 \mathrm{~km}$ height and a vertical N-S section taken $20 \mathrm{~km}$ west of the radar. We note only relatively few ground strokes in all the cells active at that time, about $90 \%$ of all strokes are $\mathrm{IC}$-strokes $\left(\mathrm{F}_{\mathrm{IC}}=0.88\right)$. This illustrates the 

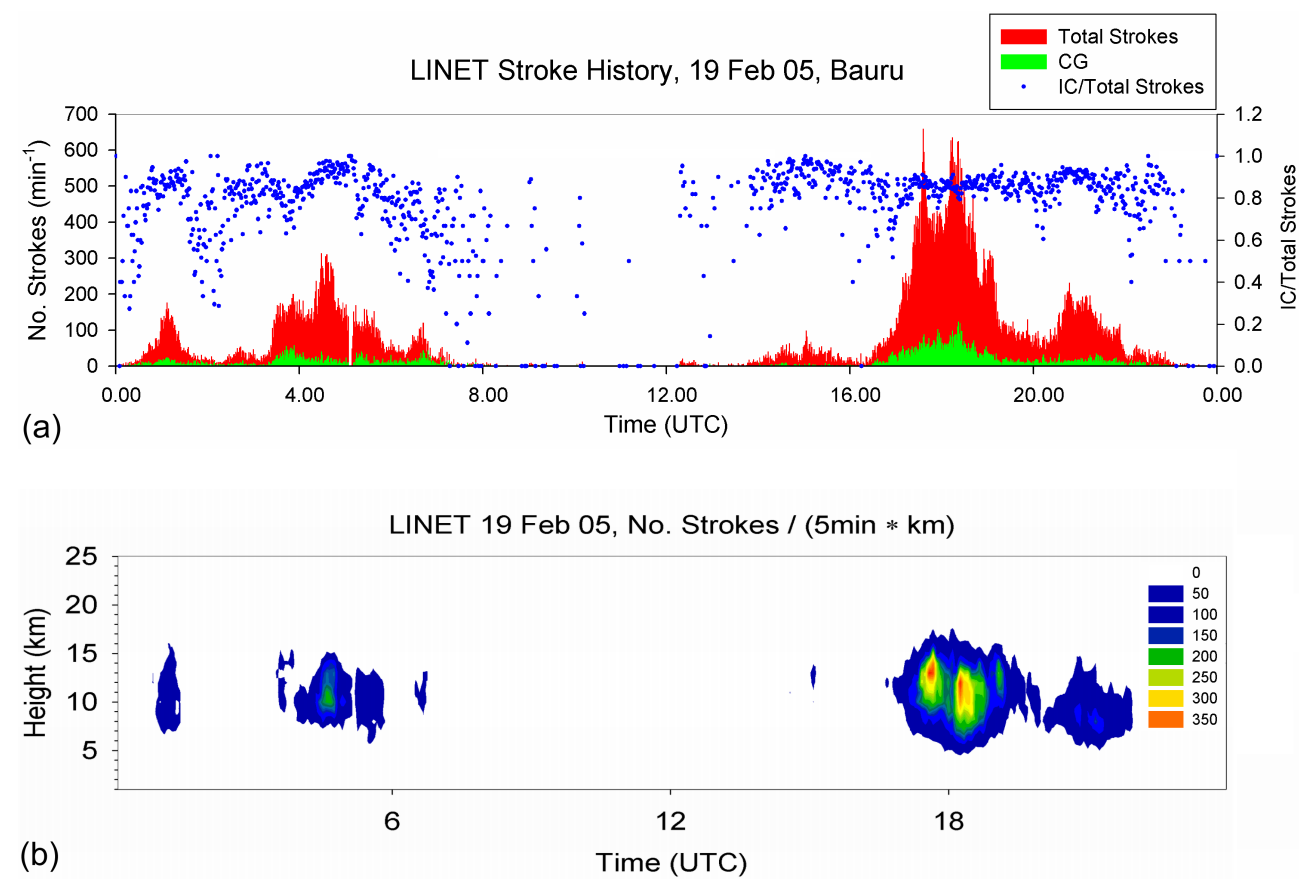

Fig. 6. (a) Time series of IC and CG stroke number per minute and IC/Total stroke fraction on 19 February 2005 in the discrimination area (D) as shown in Fig. 2. (b) Vertical distribution of stroke numbers for the same events as in (a).

Table 2. The different areas of analysis used in N-Australia.

\begin{tabular}{llll}
\hline Area & Description & Size & \\
\hline A & Overall area of analysis & $6^{\circ} \times 6^{\circ}$ & \\
& & Longitude: & $128.0^{\circ}$ to $134.0^{\circ}$ \\
& & Latitude: & $-9.0^{\circ}$ to $-15.0^{\circ}$ \\
D & CG-IC discrimination area & $120 \mathrm{~km}$ around stations & \\
I & Inner area of analysis & $1.6^{\circ} \times 1.6^{\circ}$ & $130.3^{\circ}$ to $131.9^{\circ}$ \\
& & Longitude: & $-11.5^{\circ}$ to $-13.1^{\circ}$ \\
\hline
\end{tabular}

general characteristics of a large fraction of IC strokes found for the Brazilian storms. The stroke positions correlate well with precipitation structure, especially the IC positions are all detected within the main precipitation core of moderate radar reflectivity aloft. This is in agreement with the riming graupel - ice particle collision non-inductive charging mechanism. The high reflectivity region is mostly located below 6-7 km and thus below the center of the IC-stroke activity. The cell shown in the vertical section is one of the most intense ones and extends up to $18-19 \mathrm{~km}$ in height.

For each stroke location error bars indicate the accuracy of the location procedure as described above from the $\chi^{2}$ minimization in Eqs. (1) and (2). The ground stroke position errors are very small, the mean value amounts to $40 \mathrm{~m}$ for the data points shown in Fig. 7. Thus the size of the error bars is smaller than the size of the plotting symbols so it cannot be indicated. The positions of the intra-cloud strokes are somewhat more erroneous. The mean horizontal error is around $350 \mathrm{~m}$ whereas the mean vertical error is $2.6 \mathrm{~km}$. But, as the error bars do not exceed the radar observed cloud top in the specific case shown here, all IC-sources originate from within the cloud. In general, the largest errors are connected to the vertical position determination.

As can be seen from Fig. 5 there are IC stroke locations above the maximum radar observed cloud top heights. Due to the relatively large errors in vertical position most of these sources are likely to arise from within the cloud. On the other hand, some of those very high strokes could indeed extend out of the cloud top into the stratosphere as gigantic jets or developing channels towards the ground outside the cloud as "bolt-from-the-blue" (BFB) like recently demonstrated by Krehbiel et al. (2008). As shown by Pasko et al. (2002), 

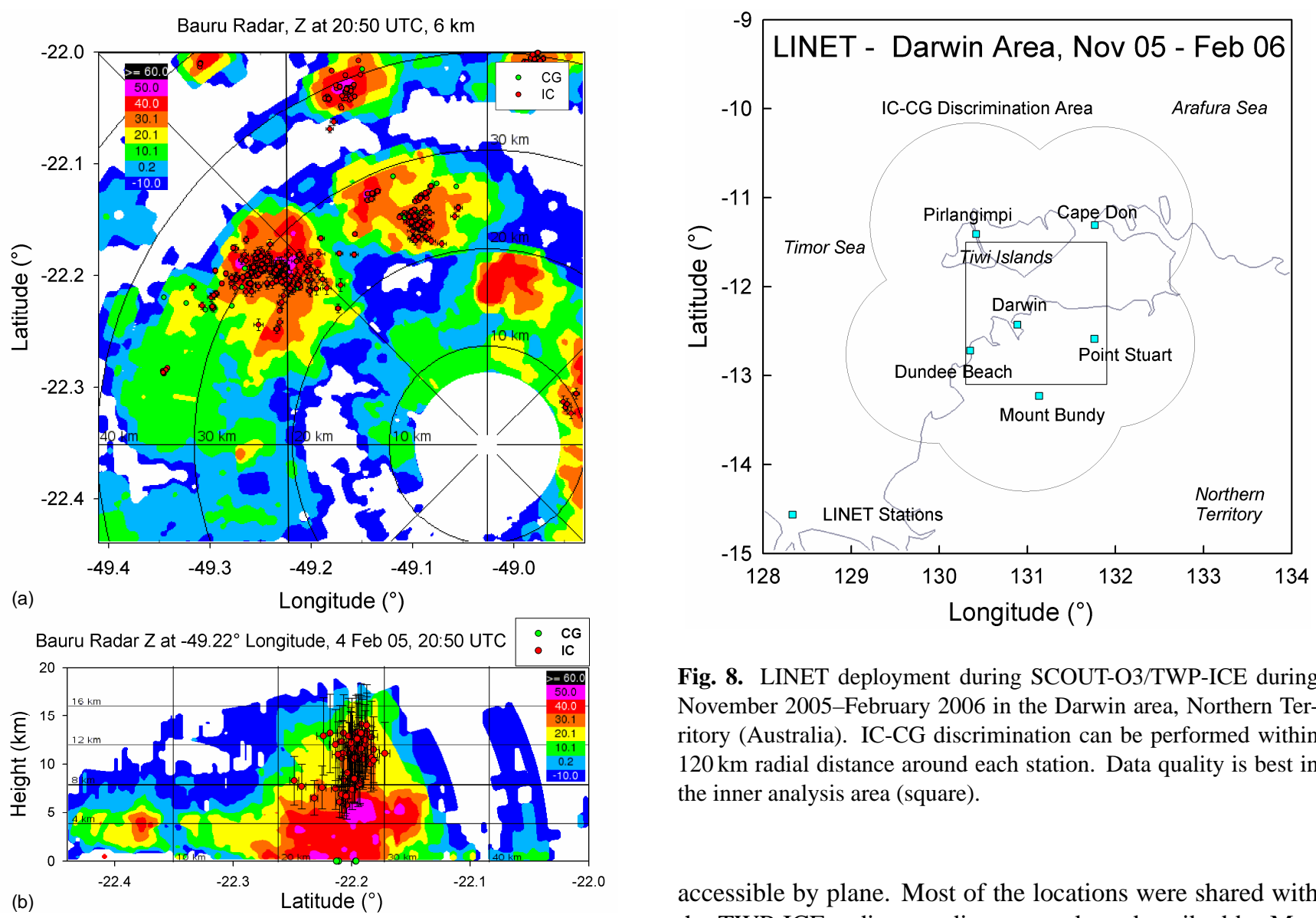

Fig. 8. LINET deployment during SCOUT-O3/TWP-ICE during November 2005-February 2006 in the Darwin area, Northern Territory (Australia). IC-CG discrimination can be performed within $120 \mathrm{~km}$ radial distance around each station. Data quality is best in the inner analysis area (square).

Fig. 7. (a) Horizontal (6 km AGL, top panel) and (b) vertical section ( $49.22^{\circ}$ longitude, $20 \mathrm{~km}$ west of radar site, bottom panel) of Bauru radar reflectivity through major storm cell on 4 February 2005 at 20:50 UTC and position of IC (red) and CG (green) strokes during a 4 min time interval around the radar scans (strokes in the vertical section from a $4 \mathrm{~km}$ wide slice). Horizontal and vertical error bars for each stroke location are indicated.

gigantic jets can be accompanied by impulsive re-brightening and VLF emissions.

\subsection{The SCOUT-O3/TWP-ICE network in the Darwin area/Australia}

During the period 12 November 2005-15 February 2006 the LINET system was operated in the Darwin area in the Northern Territory of Australia. The network was set up in a collaborative effort of DLR and the Australian Bureau of Meteorology at different sites around Darwin. The CPOL radar was located at Gunn Point NW of Darwin, thus providing polarimetric radar observations of thunderstorms from the inner LINET area. The LINET stations were located at Darwin, Point Stuart, Cape Don, Pirlangimpi, Dundee Beach and Mount Bundy (see Fig. 8). Some of these sites (Pirlangimpi and Cape Don) were rather remote from Darwin and only 

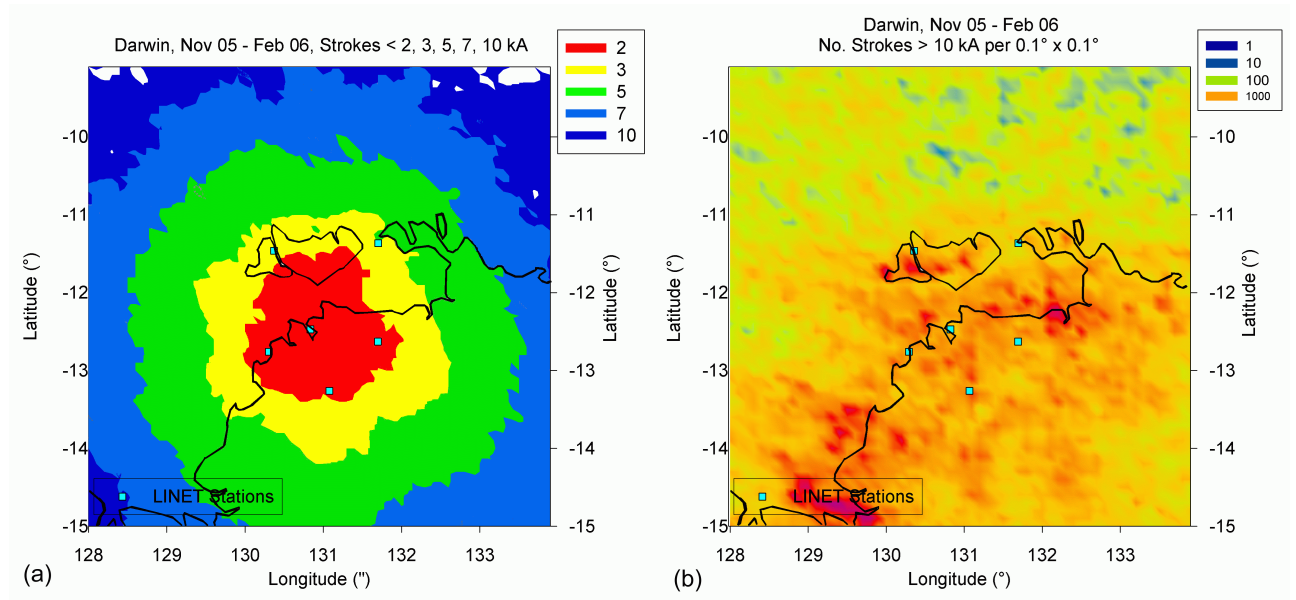

Fig. 9. (a) Detection area for strokes smaller than the indicated amplitude values and (b) stroke statistics for events exceeding $10 \mathrm{kA}$ in peak current amplitude from all stroke types during all experimental days from the period 12 November 2005 till 15 February 2006 in the Darwin area.

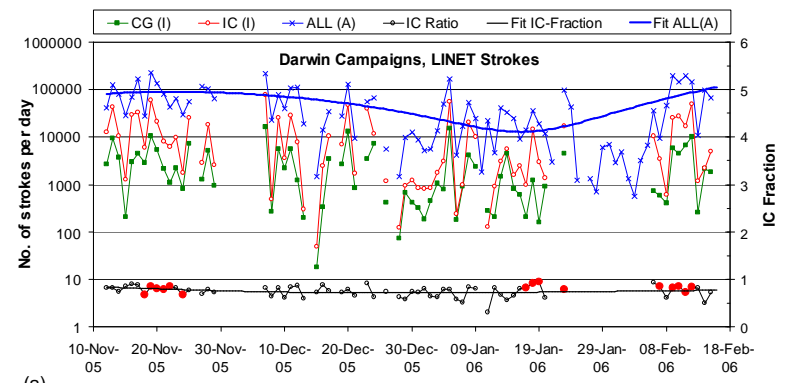

(a)

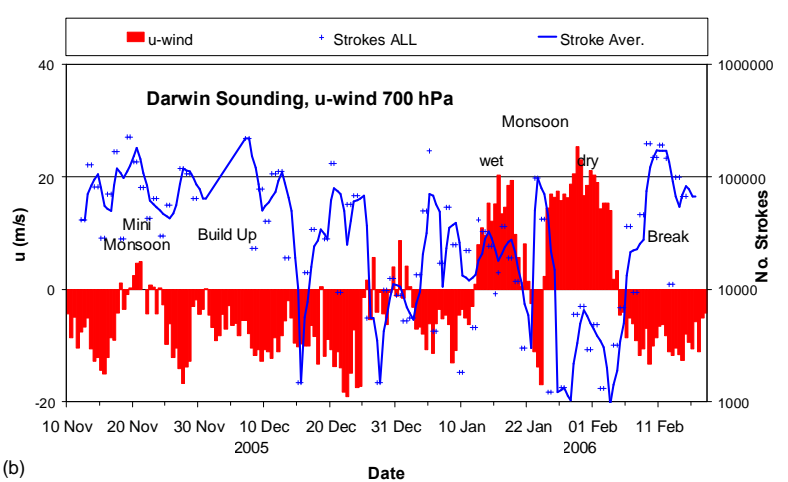

Fig. 10. (a) Daily number of strokes during the experimental period from November 2005 to February 2006 in the Darwin area as inferred from LINET measurements. CG and IC strokes from the inner area (I) are shown while the "ALL" data are observed within the wide box area (A). 3rd order polynomial fits show long-term trends. Red dots indicate the "core" data set as selected for detailed analysis with six stations being operative. (b) W-E zonal (u) wind component at $700 \mathrm{hPa}$ derived from the regular daily Darwin soundings at 00:00 and 12:00 UTC and daily stroke numbers in overall area $\mathrm{A}$ as in (a) approximated by 4 th order gliding average. the Arafura Sea in the north and the Timor Sea in the northwest. The decrease over land towards the south-east of the area is less pronounced. This general behavior is in qualitative good agreement with the lightning maps from Kuleshov et al. $(2002,2006)$ for the Australian continent (not considering the oceanic parts) derived from ground based flash counters and satellite data and also with the OTD and LIS satellite based lightning statistics (Christian et al., 2003). A comprehensive study of the convective systems around Darwin performed by Keenan and Carbone (1992) states that sea and land breezes are important as initiation mechanisms for deep convection in all the different flow regimes observed.

An overview of the measurements taken from 12 November 2005 till 15 February 2006 is presented in Fig. 10. This period covers a great part of the North-Australian monsoon season, except for the very first onset and last retreat parts. Climatologically, the wet season in the area occurs between approximately October and April (May and Ballinger, 2007). The build-up phase of the monsoon is characterized by a relatively weak early phase with only shallow storms developing and a mature phase with deep and heavy convection. The LINET measurements started during this mature buildup phase characterized by a high lightning intensity. Figure $10 \mathrm{~b}$ shows a time series of zonal W-E wind component at $700 \mathrm{hPa}$ derived from the Darwin operational soundings at 00:00 and 12:00 UTC (local time $=\mathrm{UTC}+9.5 \mathrm{~h}$ ). According to May and Ballinger (2007) this parameter is a good indicator of the pre-monsoon (build-up) and break period flow regimes of continental influence with easterly (negative $u$ ) winds and the monsoon regime of maritime character with westerly (positive u) wind components. During the build-up phase the monsoon trough is located north of Darwin. Due to the prevailing easterly airflow during the build-up phase heavy convection can develop during the day, some of regular 


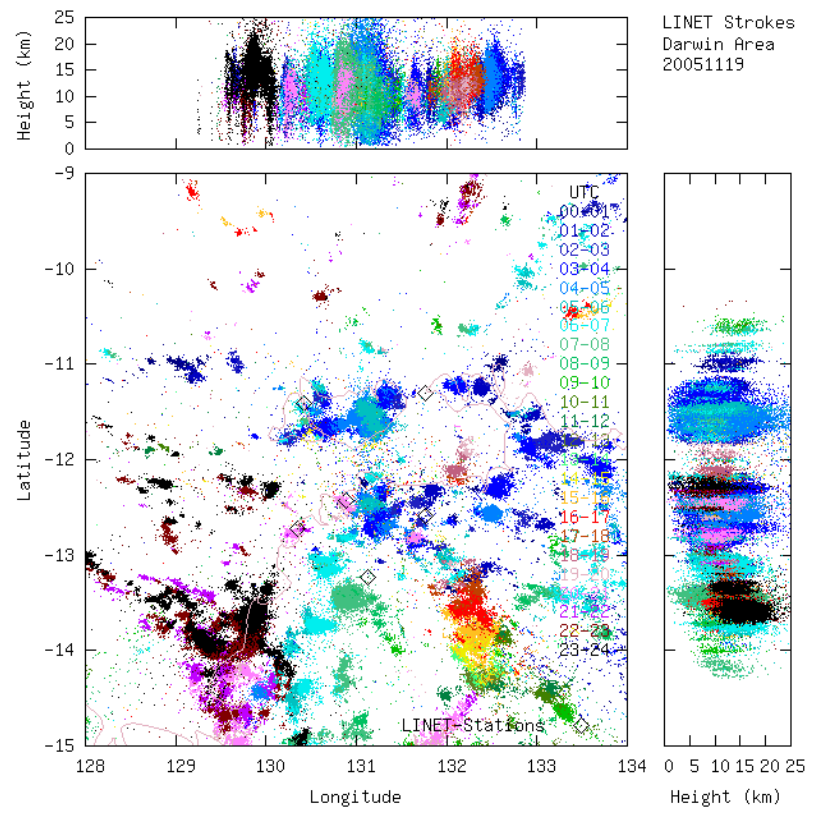

Fig. 11. Evolution of lightning activity in the Darwin area measured by LINET on 19 November 2005. Stroke locations for all types are shown in the Lat/Lon panel while the vertical sections show IC strokes only.

character like "Hector" over the Tiwi islands. An episodic interruption was the so-called "mini-monsoon" as described by Allen et al. (2008) which was attributed to the passage of a Rossby wave from the south so not representing a real monsoon.

The general trend lines in Fig. 10a as introduced as 3rd order polynomial fits of the data reflect the long-term overall picture of the differences of the pre-monsoon/monsoon/break pattern of high/moderate/high lightning intensity. We will come back to the trends in stroke number when comparing the properties of the different regions to each other. The general trends of the stroke rates are associated with a slightly varying IC-fraction indicating that the intense build-up and break period (continental) storms exhibit little higher ICfraction than the monsoon period (maritime) storms. On average the IC-fraction is 0.82 as derived from the "core" data set of the highest quality data where all six stations were operative and appreciable lightning activity was observed in the inner observation area.

More details of the monsoon cycles are retained in the comparison shown in Fig. 10b using a 4th order gliding average of the overall lightning data thus demonstrating some striking inter-relations between lightning and the monsoon regime. It can be noted that another period of beginning (suppressed or dry) monsoonal influence occurred from 26 December 2005 till 3 January 2006. Lightning activity was reduced to a minimum, the few cells observed were rather weak, did not extend to large heights and were scattered over the area. From 3-12 January 2006 easterly (build-up) flow conditions were prevailing again accompanied by some deeper, propagating storms including a squall line on 5 January 2006 which caused the corresponding peaks in lightning activity (Fig. 10a). The period 13-21 January 2006 was characterized by strong westerly flow components of the active and wet main monsoon phase. This is a period of reduced lightning activity of up to one order of magnitude but still much more than during the dry spells. There is a strong oceanic influence on the convection which was not extending that high up as in the build-up and break phases. On 22 and 23 January a short break period is noted with intense cells but on 24 January there was a complete change to nearly lightning-free conditions of a suppressed monsoon. Some lightning activity was observed over the ocean in the far northern part of the observation area (A). These conditions lasted until 5 February and were terminated by another, longer lasting break period at 6 February. This abrupt change can clearly be noted in Fig. 10b in both, the wind change to easterlies and the increasing lightning activity.

The LINET lightning measurements from the Darwin area offer the opportunity to compare tropical lightning under both, oceanic and continental conditions. As noted before, the main difference is the up to one order of magnitude lower stroke rate produced by the maritime convection during the active monsoon compared to the continental cases. Especially we note that there is practically no difference in IC-fraction between the maritime storms from the active monsoon during 13-21 January (mean $\mathrm{R}_{\mathrm{IC}}=0.76$ ) and the continental storms from the other periods. Qualitative similar results for the overall lightning activity in the Darwin area were reported by Williams et al. (1992) and Rutledge et al. (1992) from the lightning measurements performed during DUNDEE (Down Under Doppler and Electricity Experiment) in 1988-1990. During the Maritime Continent Thunderstorm Experiment (MCTEX) during November-Decemeber 1995 (Keenan et al., 2000) the electrical and microphysical evolution of the Hector convection was studied in detail (Carey and Rutledge, 2000). The "Hector" system is a regularly occurring storm complex driven by the sea breeze and thunderstorm outflows over the Tiwi Islands north of Darwin. It was shown that total flash rate and total ice mass were highly correlated to each other.

As a typical example of the convective activity Fig. 11 shows the diurnal lightning summary for 19 December 2005 during the monsoon build-up phase. The overall structure is quite patchy and reflects the short life time of the convective cells. The activity on this day occurred close to the coastline as well as inland but also a well developed Hector system is present over the Tiwi islands. We also note a different degree of intensity (number of strokes) of the cells. The most intense cells (in horizontal and vertical extent) are found over the Tiwis, close to Darwin and at the coast in the SW of the observation area. 


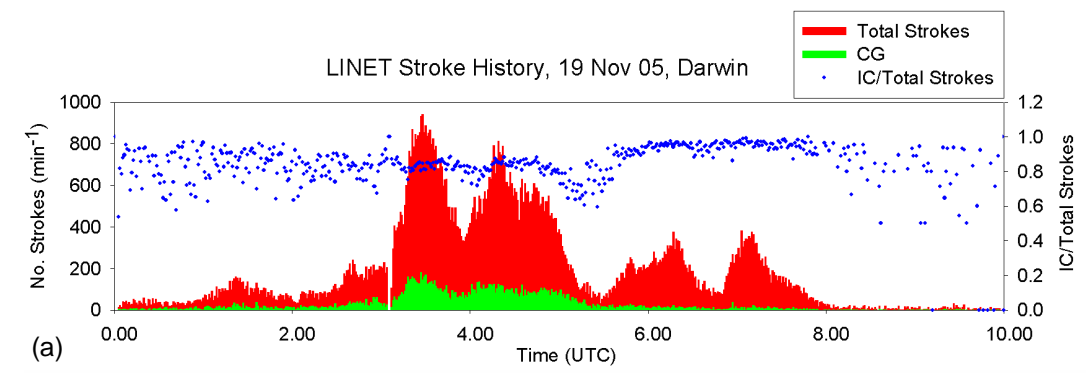

LINET 19 Nov 05, No. Strokes / (5min*km)

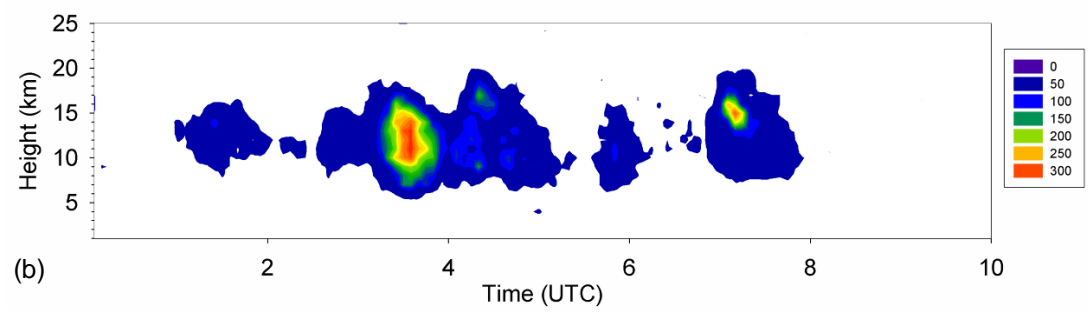

Fig. 12. (a) Time series of total (IC + CG) and CG stroke number and IC/Total stroke fraction on 19 November 2005 in the discrimination area (D) as shown in Fig. 8. (b) Vertical distribution of stroke numbers for the same events as in (a).

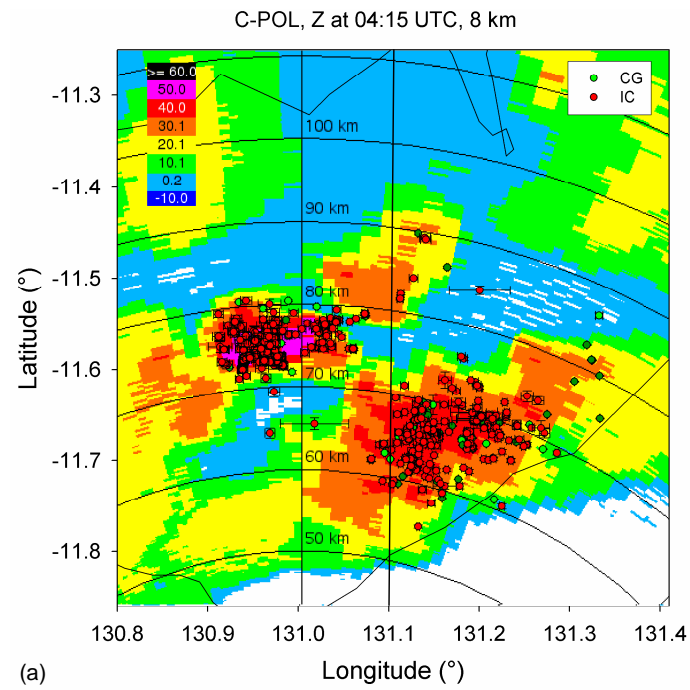

(a)

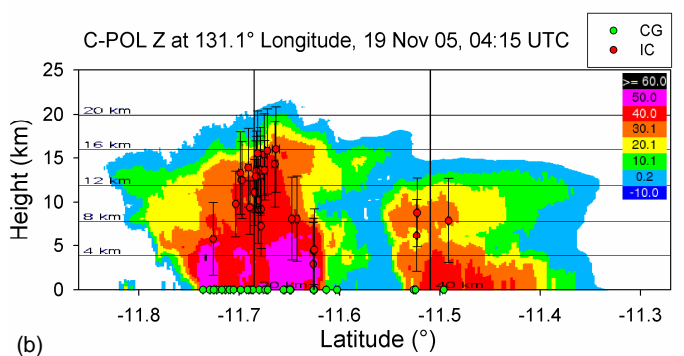

Fig. 13. (a) Horizontal ( $8 \mathrm{~km}$ AGL) and (b) vertical section $\left(131.1^{\circ}\right.$ longitude) of C-POL radar reflectivity through major Hector storm cell on 19 November 2005 at 14:15 UTC and position of IC (red) and CG (green) strokes with error bars during a 1-min (horizontal section) and 4 min (vertical section) time interval around the radar scans (strokes in the vertical section from a $4 \mathrm{~km}$ wide slice).
The IC and CG time series and the corresponding vertical IC stroke density evolution on 19 November 2005 is shown in Fig. 12 for the period 00:00-10:00 UTC (09:30-19:30 local time). Several bursts of lightning intensity can be distinguished, the two major events occurring between 03:00 and 05:00 UTC. Note from Fig. 11 that these bursts are made up by several cells occurring at the same time. The IC fraction is always high and most of the time larger than 0.8. During the later two bursts it is even close to 1 . All the bursts are also clearly visible in the vertical cross section shown in Fig. 12b. The first burst at 03:30 UTC is the most intense one and high IC densities extend through a large height interval between 7 and $16 \mathrm{~km}$. Activity in the later bursts tends to be concentrated at the higher levels from 14 to $17 \mathrm{~km}$ height.

An example of the lightning activity within the strong Hector convection is shown in Fig. 13. The radar reflectivity as measured by the C-POL radar of BMRC located in Gunn Point (NE of Darwin) at 04:15 UTC shows a complex of storm cells over the Tiwi islands. Maximum reflectivity was slightly exceeding $60 \mathrm{dBZ}$ and the maximum cloud top ( $0 \mathrm{dBZ}$ contour) of the southern and most vigorous cell was at $21 \mathrm{~km}$ height. Lightning was concentrated within the two major cells which were composed of several updrafts reflected by the cellular structure of radar reflectivity visible in the horizontal as well in the vertical section (southernmost cell). Horizontal as well as vertical error bars are also indicated for each of the stroke locations. The horizontal section contains all strokes measured during the one-minute time interval centered around the radar scan time. The mean errors in horizontal position of the CG strokes range up to $100 \mathrm{~m}$ (depending on direction) whereas those of the IC components amount up to $600 \mathrm{~m}$. In the special case shown in Fig. 13 the 


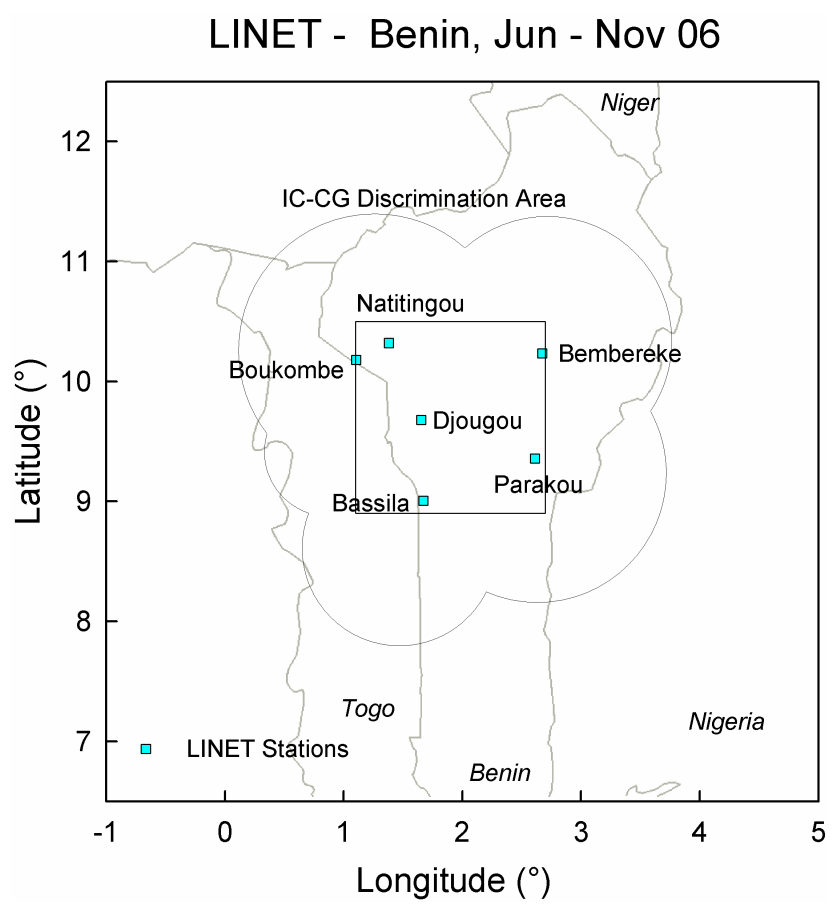

Fig. 14. LINET deployment in AMMA during June-November 2006 in the Djougou area in Benin (W-Africa). IC-CG discrimination can be performed for $120 \mathrm{~km}$ radial distance around each station. Data quality is best in the inner analysis area (I).

mean vertical error is around $6 \mathrm{~km}$. Thus vertical errors are relatively large possibly induced by the position of the storm relative to the stations but also due to the relatively high emission altitudes. Therefore, in Fig. 13b only those IC strokes having vertical position errors smaller than $5 \mathrm{~km}$ are shown. These strokes fit well into the "graupel" part of the reflectivity contours with moderate radar reflectivity values thus into the supposed area in-between the graupel and the ice crystal part of the cloud. We note that the strokes shown here can in general be regarded as constituents of more complex discharge processes. But, for the purpose of the present paper, we will not investigate the fine structure of the grouping of strokes to flashes any further.

\subsection{The AMMA network located in the Djougou area in Benin/W-Africa}

During the rainy season of 2006 LINET participated in the AMMA (African Monsoon-Multidisciplinary Analysis) campaign in W-Africa. AMMA is an international project aiming at improving the understanding of the West African monsoon (WAM) system (Redelsperger et al., 2006; Janicot et al., 2008). The AMMA observing program covers daily to interannual time scales and performed a special observing period (SOP) during June-September 2006 focusing on wet monsoon processes. The LINET network was deployed to the larger Djougou area in Benin and set up in a collaborative effort between DLR and the University of Abomey-Calavi. The area around Djougou was elected a major mesoscale observing site equipped with a variety of ground based systems and was also hosting a secondary AMMA operation center. During the rainy season the French polarimetric radar Ronsard was operated in the same experimental area. The radar was installed in Kopargo close to Djougou. Thus, similar to the other configurations, the thunderstorm systems could be observed simultaneously by radar and lightning detection. As shown in Fig. 14 the LINET stations were located at Djougou (central station), Natitingou, Boukombe, Parakou, Bassila and Bembereke. The first 4 locations had nearly continuous power supply whereas Bassila and Bembereke suffered from regular power cuts during late nighttime and during the morning, thus fortunately during the convectively less active hours of the day. But anyway, data analysis by TOA method is possible with at least 4 stations operating simultaneously. On the other hand, an occasional failure of the central station in Djougou caused additional problems with the $\mathrm{IC} / \mathrm{CG}$ discrimination as in this case the mean distance between stations is rather large.

As for the other regions the different areas of analysis are shown in Table 3. The inner region (I) is nearly coincident with the $2 \mathrm{kA}$ detection limit shown in Fig. 15a. Due to the similar network geometry the detection efficiencies are similar to those in the other regions of this study.

Figure 15b shows the regional statistics derived from all stroke events with peak currents in excess of $10 \mathrm{kA}$ during the whole observation period. We note a region of enhanced lightning occurrence in the NW parts of Benin extending further westward over Togo and eastern parts of Ghana. This feature is in principle agreement with the OTD and LIS satellite long term observations (Christian et al., 2003; Mach et al., 2007). A possible reason for this feature is orographic forcing of thunderstorms in the area of the Togo mountains and the Atakora mountains in the NW parts of Benin. On the other hand, the south-eastern parts of Benin are characterized by less lightning activity. This is in agreement with the long-term precipitation patterns and also the vegetation characteristics in that region known as the "Dahomey gap". This is a relatively dry savanna region which interrupts the otherwise zonal West-African rain forest. Vollmert et al. (2003) explain this feature in terms of cool ocean water at the coast and a divergence of the low level south-westerly monsoon flow pattern.

The overall lightning activity was largest at the beginning of the observation period from end of June to beginning of July (Fig. 16). The general trend was slightly decreasing with some variability probably due to easterly wave activity. But major breaks did not occur until end of October when the convective season ended and the ITCZ (Inter-Tropical Convergence Zone) retreated towards the south. This shift of the convective WAM region is well visible in a corresponding shift of the lightning activity, as shown in Fig. 17. The daily mean latitude and longitude position of all strokes 

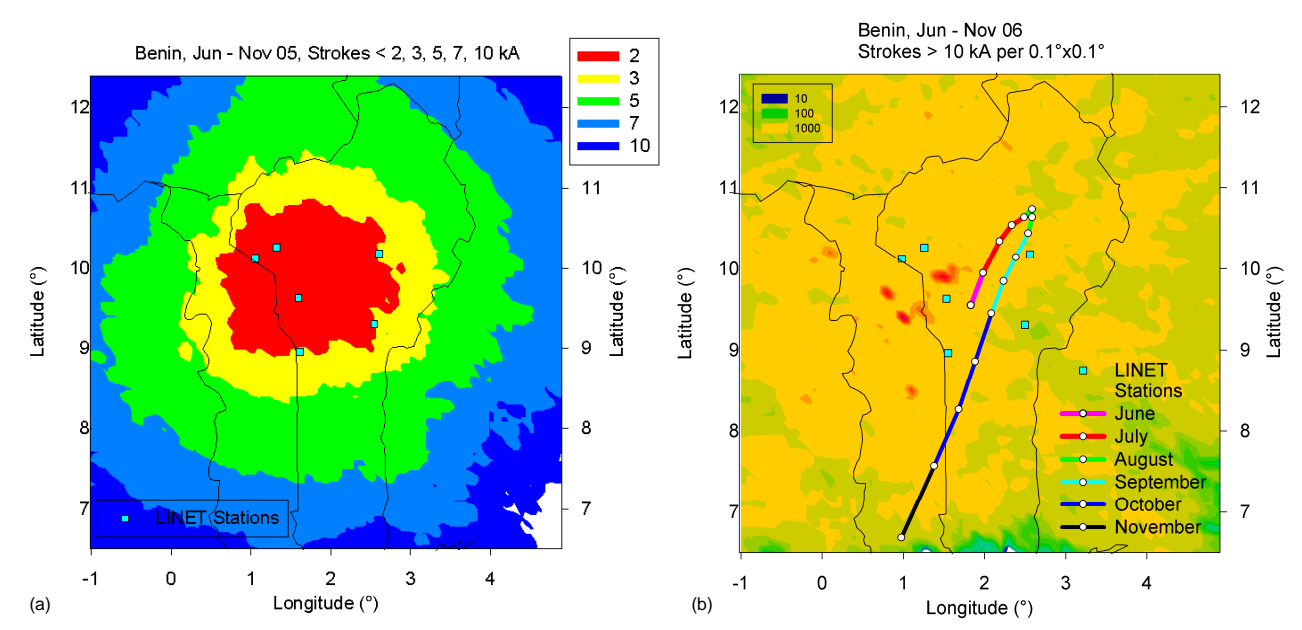

Fig. 15. (a) Detection area for strokes smaller than the indicated amplitude values and (b) stroke statistics for events exceeding $10 \mathrm{kA}$ in amplitude from all stroke types during all experimental days from the period 18 June till 18 November 2006 in Benin. The track of the trend lines of the daily mean stroke positions from Fig. 17 is shown as evolving during the observation period. Time between tick marks is 10 days.

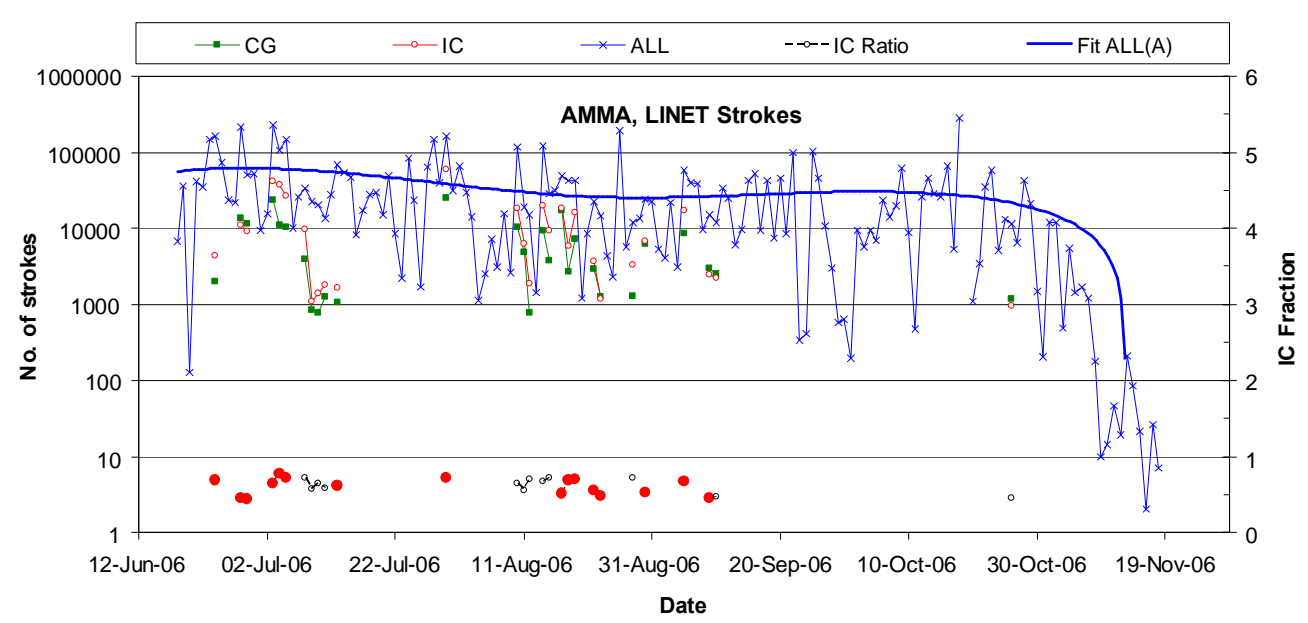

Fig. 16. Daily number of strokes during the experimental period from June 2006 to November 2006 in the Benin area as inferred from LINET measurements. CG and IC strokes from the inner area (I) are shown while the "ALL" data are observed within the wide box area (A). Red dots indicate the "core" data set as selected for detailed analysis with six stations being operative. 3rd order polynomial fit of the "ALL" data shows long-term trend.

measured (including those outside of area A) shows a clear $\mathrm{S}-\mathrm{N}-\mathrm{S}$ movement. This is also indicated by the track of the mean position in Fig. 15b. Note that due to the decreasing stroke detection efficiency with increasing distance from the network center the real position of the mean thunderstorm activity might be different from the measured activity center (i.e. extending further north during July/August). At the beginning of the observation period in mid-June the activity is moving north until during August the northernmost position is reached. In the beginning of September the activity starts to retreat towards the south. As the positions shown are simply calculated as a daily mean value and the smoothing is done based on these daily values, the track is not weighted with the total lightning activity and consequently is not coinciding with the center of all stroke observations. Interestingly, we also note a W-E-W longitudinal shift even though by far not as pronounced as the latitudinal shift. This feature is correlated with the overall stroke density pattern which seems to be connected to orographic forcing along the major mountain ridges in the area.

The IC-CG stroke discrimination is shown in summary in Fig. 16 for those observation days having activity in the inner area (I). An additional requirement for getting most reliable classification data is that the inner station at Djougou was operative. With these reductions of the total data set we derive the data lines in Fig. 16 showing generally decreasing activity 
Table 3. The different areas of analysis used in Benin.

\begin{tabular}{llll}
\hline Area & Description & Size & \\
\hline A & Overall area of analysis & $6^{\circ} \times 6^{\circ}$ & $-1.0^{\circ}$ to $5.0^{\circ}$ \\
& & Longitude: & $6.5^{\circ}$ to $12.5^{\circ}$ \\
& & Latitude: & \\
D & CG-IC discrimination area & $120 \mathrm{~km}$ around stations & \\
I & Inner area of analysis & $1.6^{\circ} \times 1.6^{\circ}$ & $1.1^{\circ}$ to $2.7^{\circ}$ \\
& & Longitude: & $8.9^{\circ}$ to $10.5^{\circ}$ \\
\hline
\end{tabular}

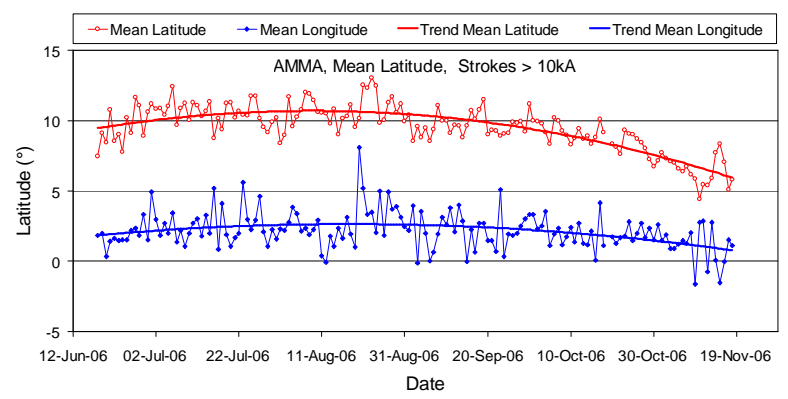

Fig. 17. Seasonal variation of the daily mean stroke positions derived from all stroke measurements including those outside of area A. The trend lines are represented by 2 nd order polynomial fits of the data.

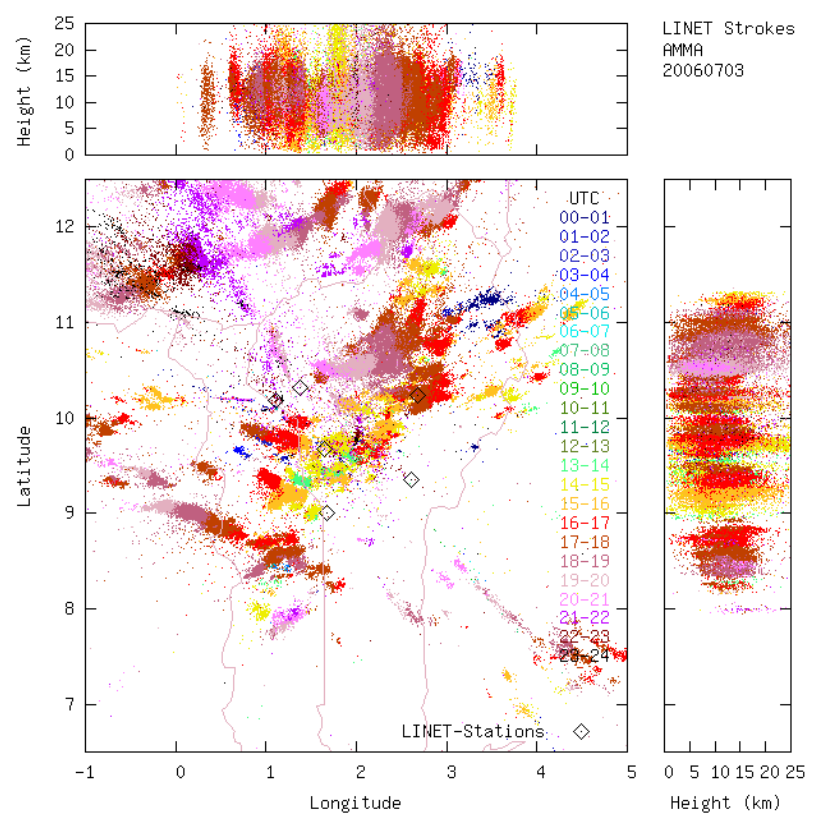

Fig. 18. Evolution of lightning activity in the Benin area measured by LINET on 3 July 2006. Stroke location for all types is shown in the Lat/Lon panel while the vertical sections show IC strokes only. with time as in the case of the larger-scale activity of all type of strokes from area A. The mean fraction FIC for all stroke events is 0.64 . This is very close to the values found for the mid-latitude convection in Southern Germany and somewhat smaller than the Brazilian and Australian values indicating a larger fraction of CG events. The best quality data was obtained with all six stations operating and appreciable lightning activity within the inner observation area. The days are marked by the red dots in the IC-fraction time series.

An example of the thunderstorms observed in the region is shown in Fig. 18. On 3 July 2006 thunderstorms rapidly developed at around 13:00 UTC within the inner observation area (see also Fig. 19). A small storm complex formed which was made up by several cells having life times of $1-3 \mathrm{~h}$. The cells moved from ESE to WNW and those in the inner area decayed shortly after 18:00 UTC. Activity was going on outside the inner area. The storms in the south had similar propagation direction as the central cells. The northern storms were part of a storm complex having slightly different propagation characteristics as it moved from NE to SW. But all the storms were imbedded in the general easterly flow.

The bulk of the IC sources was located between 6 and $16 \mathrm{~km}$ height as shown in Fig. 19. The vertical location accuracy of the network depends on the distance of the stroke events from the stations leading to a general decrease of accuracy especially outside of the inner area. This leads to a scatter of the vertical location data to be seen in Fig. 19 which includes all data points in the overall discrimination area D. The best possible assessment can be obtained from data in the inner area (I) as shown in Fig. 19. In addition to the IC events, the time series of the ground strokes is also shown. The resulting IC fraction FIC mainly varies between 0.6 and 0.8 which is close to the example from Southern Germany as shown in Fig. 26.

During the starting phase of the thunderstorm activity on 3 July 2006 the cells developed close to the center of the observation area of LINET as well as close to the French Ronsard polarimetric radar which was installed at Kopargo NNW of the central LINET station at Djougou (see Fig. 20). Two major storms can be noted in Fig. 20 a at close distance to the radar. This snapshot shows the evolution during maximum 


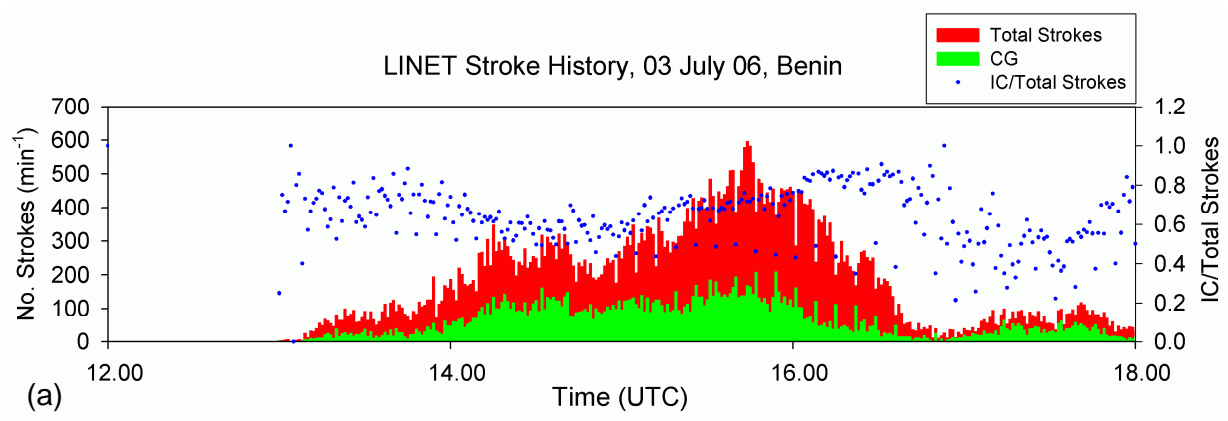

LINET 03 July 06, No. Strokes / (5min*km)

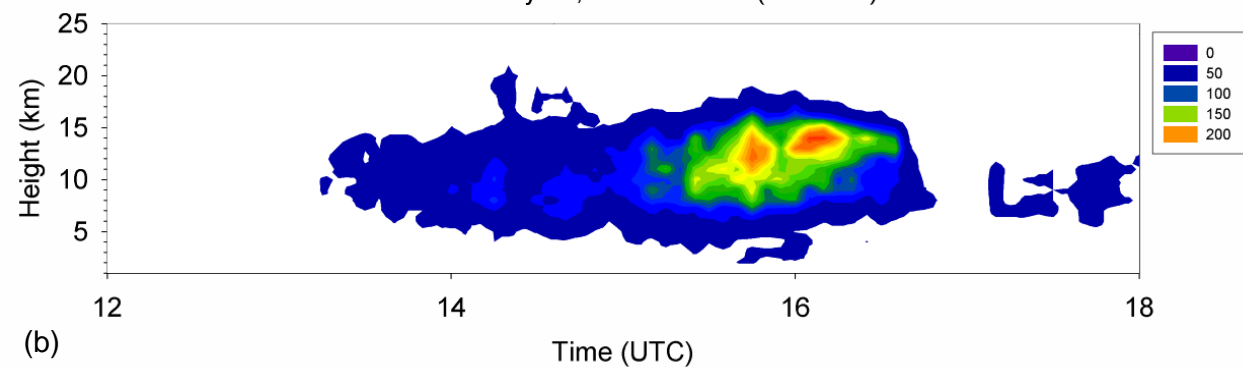

Fig. 19. (a) Time series of total (IC+CG) and CG stroke number and IC/Total stroke fraction on 3 July 2006 in the inner area (I) as shown in Fig. 14. (b) Vertical distribution of stroke numbers for the same events as in (a).

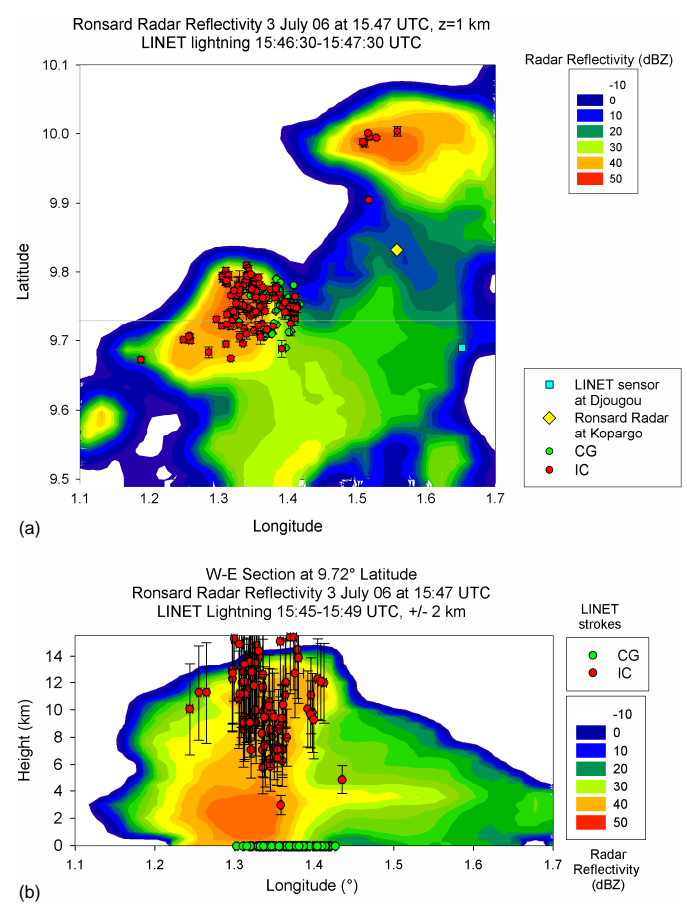

Fig. 20. (a) Horizontal (1 km AGL) and (b) vertical section $\left(9.72^{\circ}\right.$ latitude) of Ronsard radar reflectivity through major storm cells on 3 July 2006 at 15:47 UTC and position of IC (red) and CG (green) strokes with error bars during a 1 min (horizontal section) and $4 \mathrm{~min}$ (vertical section) time interval around the radar scans (strokes in the vertical section from a $4 \mathrm{~km}$ wide slice). lightning activity in the inner observation area corresponding to the time series shown in Fig. 19. The ground flashes are grouped according to the two major precipitation centers of this southern cell complex. The lightning observations from a 1-min (horizontal section) and 4-min (vertical section) time window centered around the radar scanning time are superimposed. The major cell is located WSW of the radar at that time and is moving towards WNW as is also indicated by the lightning track in Fig. 18. IC strokes are observed in good agreement with the major reflectivity center aloft between 6 and $13 \mathrm{~km}$ height. The vertical distribution covers a relatively larger height interval in accordance with the distribution of radar reflectivity. The error bars for the stroke location are also indicated on the plot. The mean horizontal CG location error is around $100 \mathrm{~m}$, mean IC error is $700 \mathrm{~m}$ in the horizontal and $4.5 \mathrm{~km}$ in the vertical dimension.

\subsection{The network in S-Germany 2005}

After the return from Brazil the lightning network was installed in Southern Germany from June 2005 to August 2005 around the DLR polarimetric radar POLDIRAD in the $\mathrm{Mu}-$ nich area. The idea was to substantially increase the existing station density of the LMU/NowCast network to achieve a local network base line in the order of $20-30 \mathrm{~km}$. The location of the stations operating in the combined network of 2005 are shown in Fig. 21. The performance of the system especially with respect to the detection of IC signals has been discussed together with some application examples in Betz et al. $(2007,2008)$. It could be shown that within the dense part 
Table 4. The different areas of analysis used in S-Germany.

\begin{tabular}{llll}
\hline Area & Description & Size & \\
\hline A & Overall area of analysis & $9^{\circ} \times 6^{\circ}$ & \\
& & Longitude: & $6.5^{\circ}$ to $15.5^{\circ}$ \\
& & Latitude: & $46.0^{\circ}$ to $52.0^{\circ}$ \\
D & CG-IC discrimination area & $120 \mathrm{~km}$ around stations & \\
I & Inner area of analysis & $2.4^{\circ} \times 1.6^{\circ}$ & \\
& & Longitude: & $10.3^{\circ}$ to $12.7^{\circ}$ \\
& & Latitude: & $48.3^{\circ}$ to $49.9^{\circ}$ \\
\hline
\end{tabular}

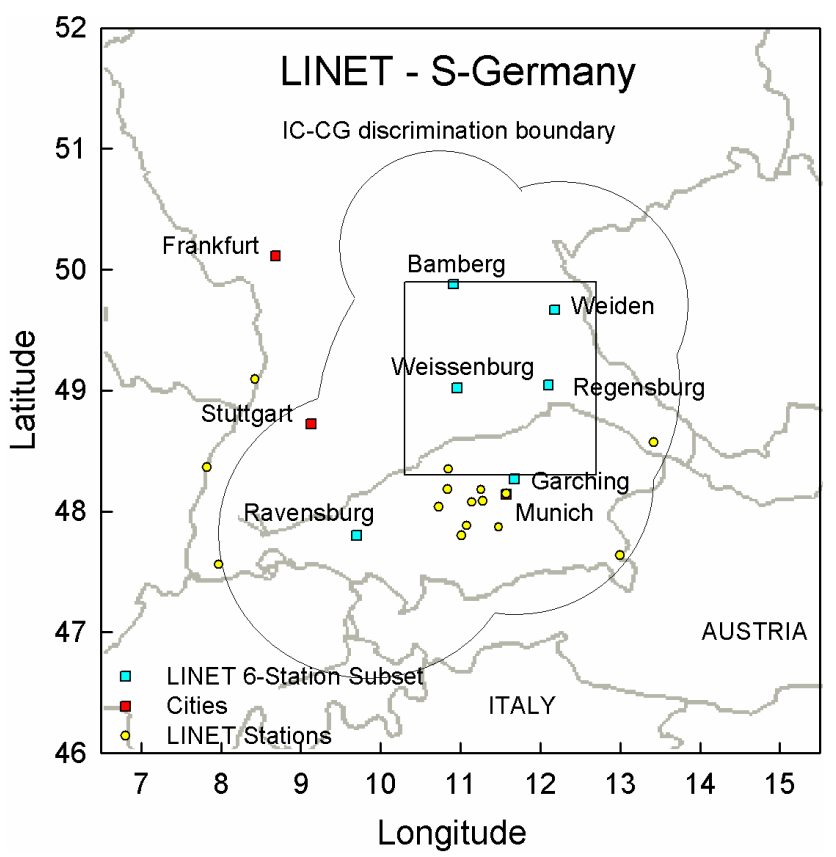

Fig. 21. Lightning stations of the DLR/LINET completing the LMU/nowcast network in Southern Germany during summer of 2005. Blue squares indicate station subset selected for analysis. IC-CG discrimination can be performed within $120 \mathrm{~km}$ radial distance around each station as indicated by the circular segments circumscribing the discrimination area (D). Data quality is best in the inner analysis square area (I).

of the network the measurement of estimated peak current as low as $1 \mathrm{kA}$ was possible. High stroke rates were found at amplitudes lower than those found for the coarser network.

In the context of the present paper we are interested in a comparison of the lightning characteristics in the different geographical regions of the world. Therefore, in the following we discuss measurements from a reduced network configuration using only a subset of 6 stations in order to ensure comparability of the results with those of the tropical networks. The detection thresholds were the same as for the tropical stations. Figure 21 shows this subset (blue squares) and the resulting discrimination boundary (D). The overall box area (A) is chosen of comparable size to the tropical areas, with increased range of longitudes according to the northerly geographical location centered around $49^{\circ} \mathrm{N}$ in latitude.

Figure 22 shows (a) the network sensitivity for strokes of different strengths and (b) the summary of the regional distribution of strokes with peak currents larger than $10 \mathrm{kA}$. The sensitivity, as derived experimentally from all the observation during the 5-month period, is rather similar to the pattern found for the other regions. Thus we can apply the same analysis method, especially using the same threshold for the regional statistics shown in Fig. 22b. The result shows qualitative good agreement with earlier statistics performed by Finke and Hauf (1996). Due to the elevated terrain of the Black Forest and the Swabian Alb, the SW part of Germany is a region of high lightning occurrence. This turns out to be a rather robust feature appearing even in relatively short term statistics as the one-season record used here. As also noticed by Finke and Hauf (1996), the other characteristics may be of more fluctuating nature being subject to a higher yearto-year variability depending on other forcing mechanisms like frontal passages or squall lines. In general, the higher mountains of the central Alps (inner Alpine dry area) in the south tend to show less lightning events. This was also documented by a 10 -year statistics from the Austrian lightning network ALDIS shown by Schulz et al. (2005). Increased lightning activity is often found in the Alpine Foreland along the northern fringes of the Alps.

The lightning activity for the convective season MaySeptember 2005 in southern Germany is shown in Fig. 23. The "ALL" category includes IC, CG and the non-classified strokes UK (unknown) for the large area (A). On the other

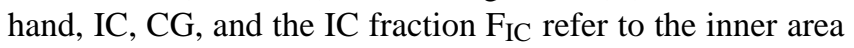
(I). The seasonal variation of lightning with rising (decaying) activity in May (September) and maximum development during July can be noted. There is appreciable scatter in the time series with an average period of 6 days between the activity maxima. This feature is due to the synoptic scale variability characterized by a change of unstable and stable air masses mostly in connection with troughs and ridges of 

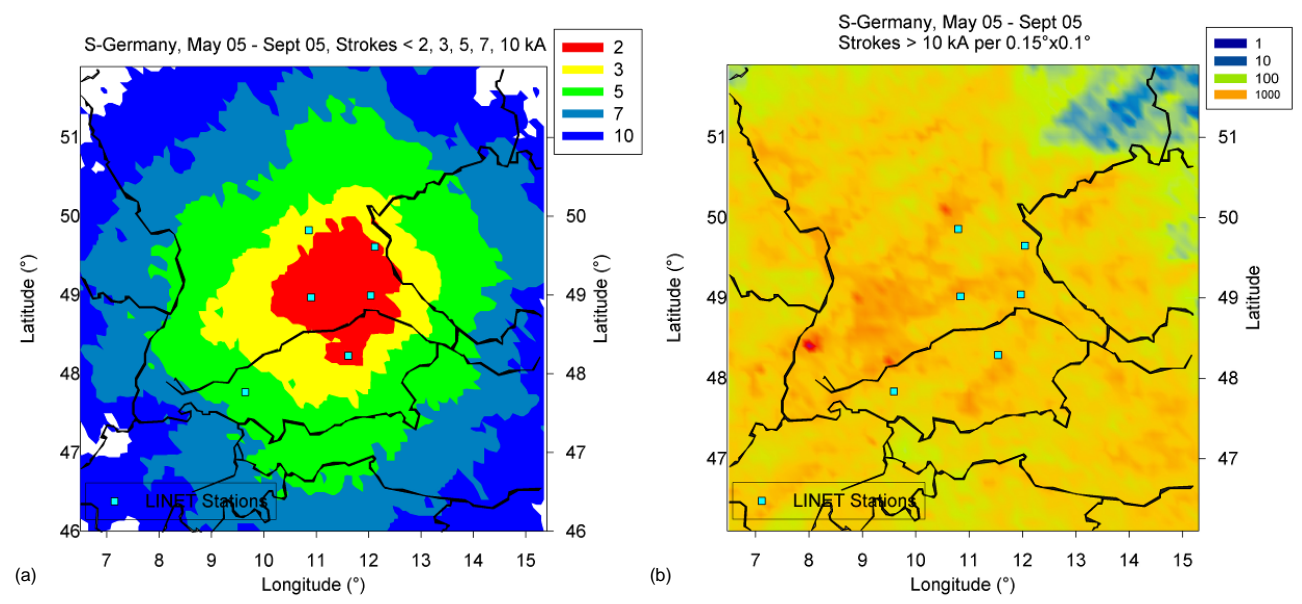

Fig. 22. (a) Detection area for strokes smaller than the indicated amplitude values and (b) stroke statistics for events exceeding $10 \mathrm{kA}$ in amplitude from all stroke types during all experimental days from the period 1 May till 30 September 2005 in S-Germany.

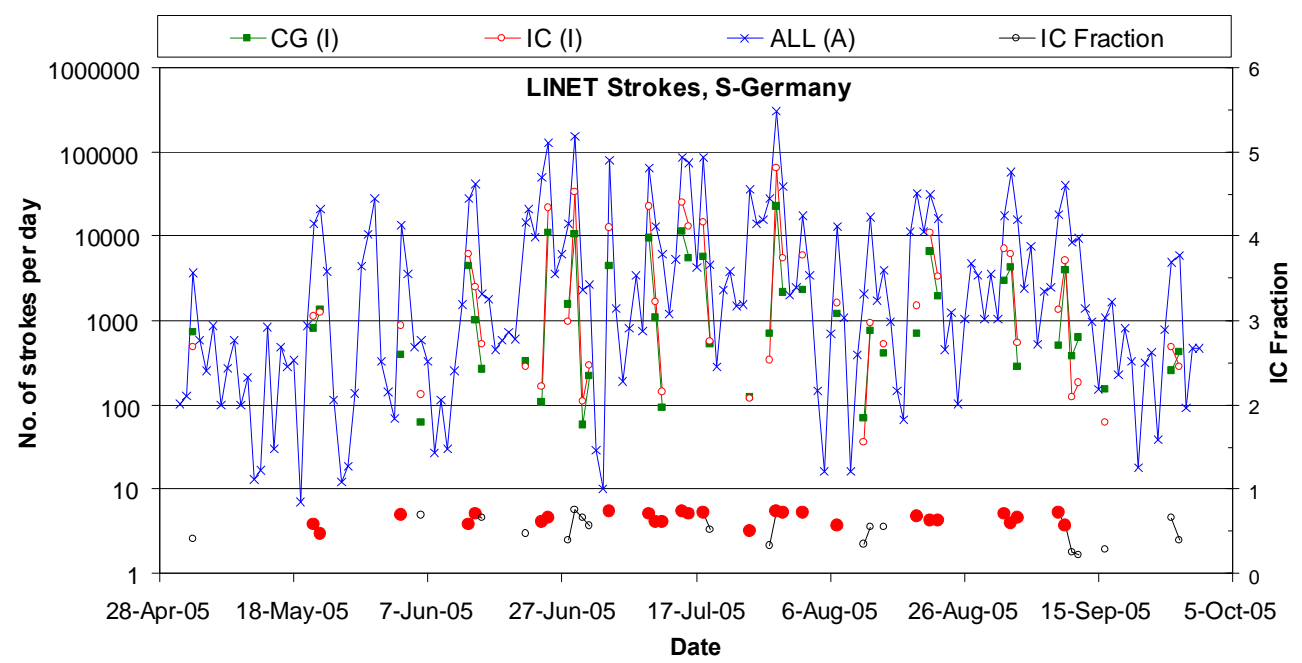

Fig. 23. Daily number of strokes during the experimental period from May to September 2005 in S-Germany as inferred from LINET measurements. CG and IC strokes from the inner area (I) are shown while the "ALL" data are observed within the wide box area (A). Red dots indicate the "core" data set as selected for detailed analysis with six stations being operative.

the Rossby wave activity in the mid-latitudes. As the IC-CG discrimination was only done in the inner area (I) we find many gaps in the data which are due to lacking thunderstorm activity in that region. We find a similar seasonal development as for the overall activity. The average IC-fraction is 0.69. Interestingly, we also find a slight seasonal variation of the IC-fraction with a trend to dominating CG strokes in the beginning and the end of the convective season. This corresponds to the smaller and less deep thunderstorms during these months with charge centers closer to the ground and thus producing an increased fraction of ground strokes. A detailed analysis of the stroke parameters has been performed with the set of "core data" marked by the red dots in Fig. 23. These are those days with best quality data from the inner area of the network.
In the following we will discuss a typical example of a European summer time convective development leading to widespread lightning activity. The strongest convective events are frequently connected to unstable air masses ahead of cold fronts as part of a pre-frontal convergence line leading to the formation of squall lines or convective complexes (e.g. Kaltenböck, 2004). Such a development also occurred on 4 July 2005 in connection with south-westerly winds at midlevels and a low level easterly flow thus leading to favourable conditions for convective line formation.

As an example of the lightning history in S-Germany Fig. 24 shows the lightning summary for 4 July 2005. The lightning activity occurs between around 11:00 UTC and 17:00 UTC. The convective pattern clearly indicates storm tracks oriented SW-NE. This feature is typically observed in 


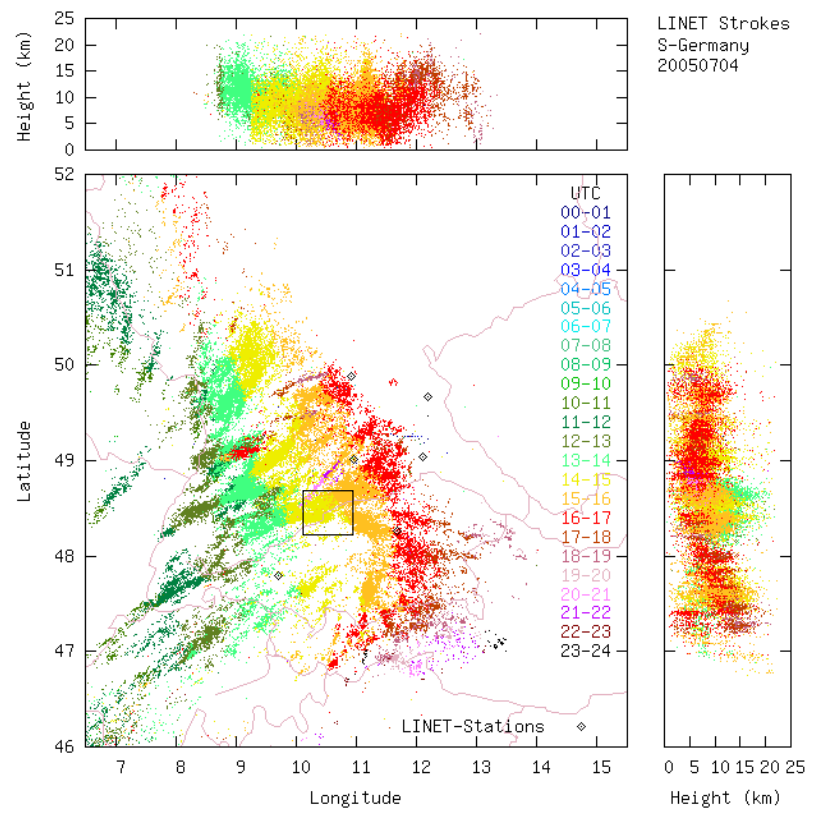

Fig. 24. Evolution of lightning activity in Southern Germany measured by LINET on 4 July 2005. Stroke locations for all types are shown in the Lat/Lon panel while the vertical sections show IC strokes only. Black square indicates radar PPI section of Fig. 25a.

deep convection at mid-latitudes when high wind speeds are present aloft in connection with a south-westerly jet stream ahead of a low pressure system approaching from the west. We also note a broadening of the storm front which happened in connection with the formation of a squall line.

A snapshot during the most intense phase of the convective development is shown in Fig. 25a. The POLDIRAD (polarization diversity radar of DLR in Oberpfaffenhofen) image of radar reflectivity at $3^{\circ}$ elevation (around $4 \mathrm{~km}$ height at the cell cores) shows two intense convective cells with maximum reflectivity of around $60 \mathrm{dBZ}$. The polarimetric data also indicate hail reaching the ground in both cells which is also supported by the vertical section in Fig. 25b through the center of the southern storm. Lightning locations for the CG and IC strokes are superimposed on the radar image. Thus, seen from the top, we note an overall coincidence of lightning and precipitation patterns with a slight tendency of lightning being present in the older storm parts on the western side of each system and less frequent in the younger cells to the east of the storms. This is also supported by the vertical section in Fig. 25b.

Peaks of the stroke activity extend basically up to $14 \mathrm{~km}$ height which is the maximum radar-observed height of the overshooting storm towers. This is demonstrated by a POLDIRAD vertical cross section (radar located at $600 \mathrm{~m}$ altitude) of radar reflectivity (see Fig. 25b) taken at 14:28 UTC through the core of the most active cell (southernmost major storm track in Fig. 24, see black box). While the light-

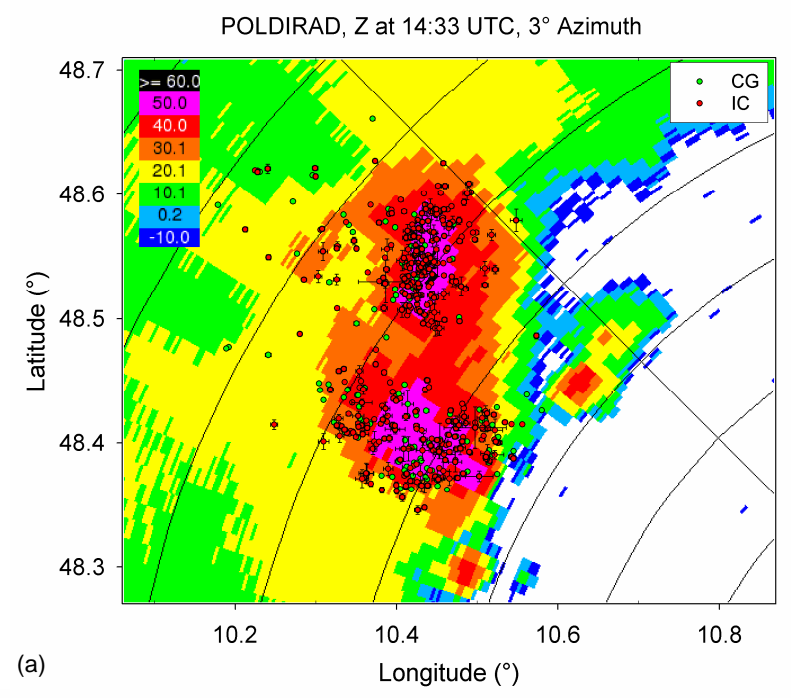

(a)

POLDIRAD, $Z$ at $298^{\circ}$ Azimuth, 4 July 05, 14:28 UTC

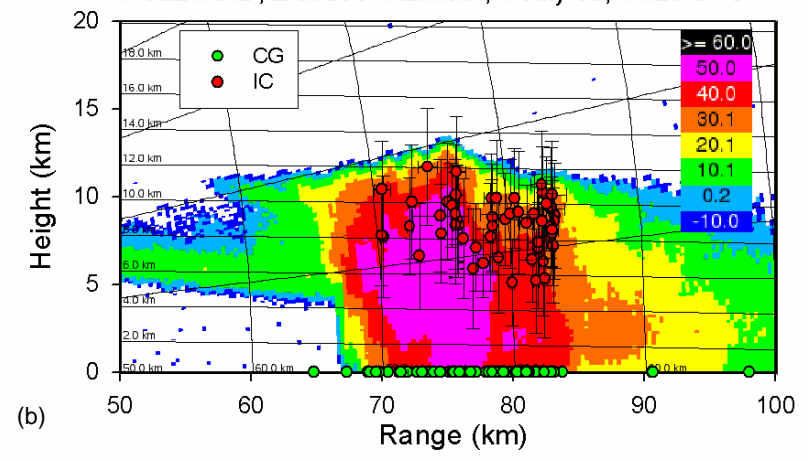

Fig. 25. (a) "Horizontal" (PPI at $3^{\circ}$ elevation) and (b) vertical section (at $298^{\circ}$ azimuth) of POLDIRAD radar reflectivity through major storm cell on 4 July 2005 at 14:33 UTC (PPI) and 14:28 UTC (RHI) and position of IC (red) and CG (green) strokes with position error bars during a 6 min time interval around the radar scans (strokes in the RHI from a $4 \mathrm{~km}$ wide slice). Only IC with vertical location error smaller than $3.5 \mathrm{~km}$ are shown.

ning overview in Fig. 24 contains all IC strokes, the radar section in Fig. 25b only considers those having vertical location errors smaller than $3.5 \mathrm{~km}$. Most of these IC stroke locations are found within the upper part of the storm's core in a region containing graupel or ice-particles (inferred from polarimetric parameters not shown here). The main updraft and hail core (reflectivity up to $60 \mathrm{dBZ}$ ) tends to contain less lightning. It extends up to $14 \mathrm{~km}$ altitude, thus indicating a high-speed updraft resulting in a cloud top overshooting of around $2-3 \mathrm{~km}$ above adjacent anvil level $(12 \mathrm{~km})$.

Error bars indicating the horizontal and vertical position errors for each stroke are also plotted in Fig. 25. In the plotting area mean CG location errors range between 100 and $140 \mathrm{~m}$. For IC the mean horizontal error is around $300 \mathrm{~m}$ whereas the mean vertical error amounts to $3.2 \mathrm{~km}$ for all strokes in the area. 

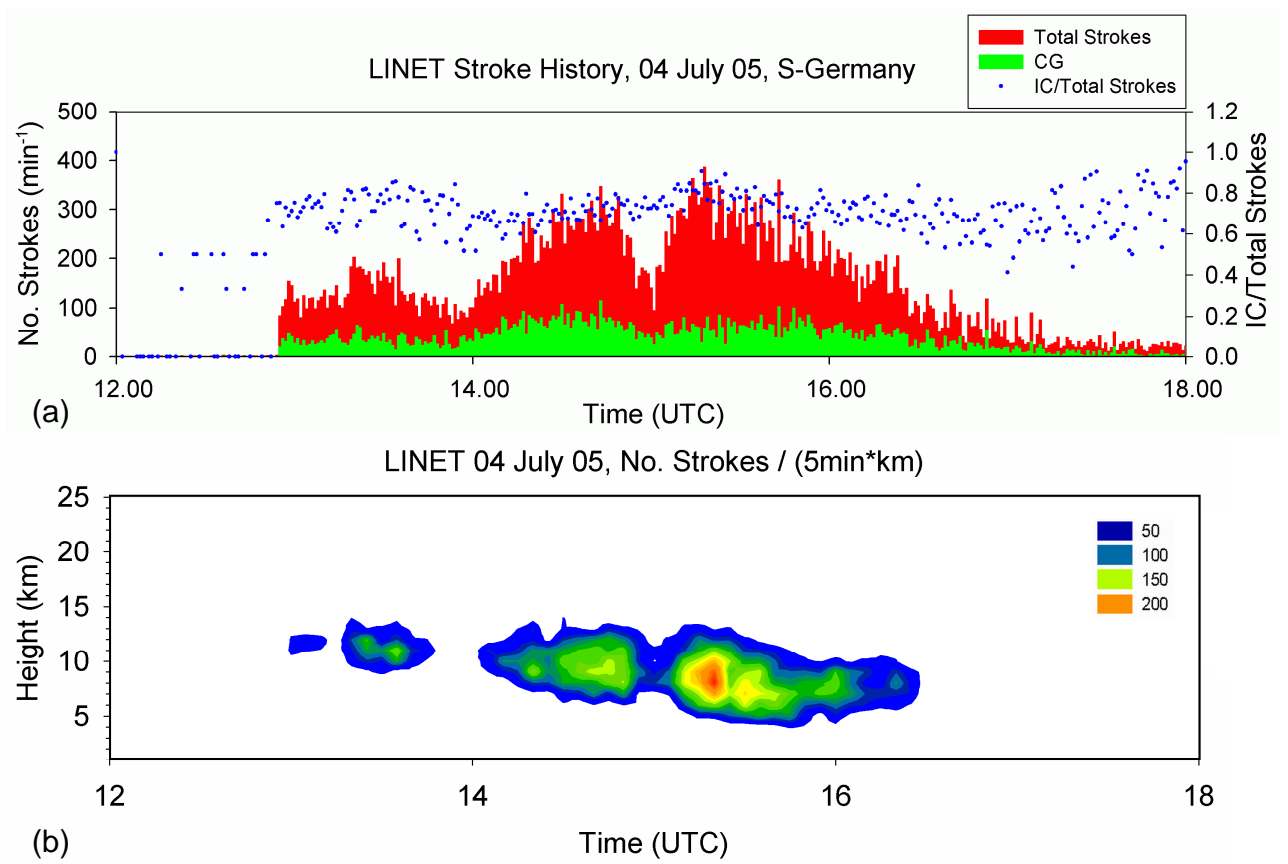

Fig. 26. (a) Time series of IC and CG stroke number per minute and IC/Total stroke fraction on 4 July 05 in the discrimination area (D) as shown in Fig. 21. (b) Vertical distribution of stroke numbers for the same events as in (a).

Similar results of the vertical distribution of VLF sources within a thunderstorm were reported by Shao et al. (2006) using the Los Alamos Sferic Array (LASA) in Florida. Instead of the magnetic flux, as is the case for the LINET sensors, LASA uses electric field change sensors. Vertical information on VLF source height can be obtained for narrow bipolar events (NBEs) only, whereas LINET does infer vertical information for all types of ICs. Both systems detect the majority of the VLF sources within the active storm regions preferably at the top of its convective turrets.

Figure 26 shows different time series of IC and CG events in the discrimination area (D). The sudden rise of activity at around 13:00 UTC is due to the thunderstorms entering the area from the SW. The IC fraction is varying approximately between 0.6 and 0.8 , thus slightly lower than observed in Brazil. Typically the IC activity extends between 5 and $14 \mathrm{~km}$, the maximum IC stroke density occurring at about $8 \mathrm{~km}$.

\section{Comparison of the different lightning regimes}

The LINET observations as described in the previous paragraph have been performed in quite different climatic regimes. These cover sub-tropical to tropical Brazil, Northern Australia with it's tropical convection of maritime and continental characteristics, the monsoon system of West-Africa (continental type) and a mid-latitude area (SGermany). Thus it is interesting to look for the basic overall characteristics in these regimes and their differences. Moreover, one can infer some conclusions on the role of the stroke characteristics for the lightning $\mathrm{NO}_{\mathrm{x}}$ production in the different regions.

\subsection{General characteristics}

The general characteristics of the lightning occurrence in the regions studied here show high intra-seasonal variability. Figure 27 summarizes the main results discussed above for the total number of strokes with peak currents $>10 \mathrm{kA}$ in the large observation area $\mathrm{A}$ in each of the regions. These areas are about the same size. Moreover, the network configurations are similar to each other leading to about the same sensitivity for stroke detection. In order to exclude effects of non-central occurrence of thunderstorms (highest sensitivity) in a possibly not large enough sample of data we restrict this comparison to stroke peak currents larger than $10 \mathrm{kA}$. A check against all available data (not shown here) has demonstrated that this does not change the results qualitatively. In order to compare the levels of lightning intensity and especially the days with maximum activity, the results are shown in terms of stroke numbers during days since start of the operations for each region instead of e.g. distribution functions. The 40-days period of observations in Brazil is rather short compared to the other periods but, nevertheless, is covering different convective conditions.

The trend lines show a kind of general level being characteristic for convection in all regions of about 8000 strokes 
Table 5. Number of observation days strongly electrically active (more than 40000 strokes $>10 \mathrm{kA}$ in the A-area).

\begin{tabular}{lc}
\hline Region & $\begin{array}{c}\text { No. days with strong } \\
\text { lightning activity }\end{array}$ \\
\hline N-Australia & 11 \\
S-Germany & 3 \\
Benin & 2 \\
Brazil & 1 \\
\hline
\end{tabular}

per day in the A-area. This corresponds typically to the months of maximum summer time convective activity in mid-latitudes (S-Germany), the minimum activity during the Australian monsoon season, a plateau shaped long term feature in Benin and a kind of mean activity in Brazil. On average, the Australian storms produce the highest daily stroke rates which are a factor of 3 above this overall mean. Responsible for that are the heavy and frequently occurring storms during monsoon build-up and break periods. A similar effect is in action in W-Africa at the monsoon onset, but the very first phase was not covered by the measurements. Thus the lightning activity is enhanced for only a factor of 2 during the period of observations. A similarly large increase in activity was observed in Brazil at the end of the observation period under the influence of unstable tropical air masses north of the SACZ.

We have to keep in mind that the average trends are influenced by the large variability of the thunderstorm occurrence in the different regions and it is rather instructive to look at the peak values. In S-Germany the activity gaps may be relatively large as there might be several inactive days in between the active thunderstorm days thus causing lower average trends. The individual thunderstorm days (during peak storm season) have rather high stroke rates and indeed, the maximum of all daily stroke numbers was observed in SGermany on 21 July 2005. This absolute maximum is even more pronounced when all stroke events including peak current values smaller than $10 \mathrm{kA}$ are included. If we define a category of strongly active days as those where stroke numbers ( $>10 \mathrm{kA}$ in area A) exceed 40000 we find from Fig. 27 the number of events as shown in Table 5. Strong lightning activity can occur in all regions within the same range of stroke number per day and area. The mid-latitude convection produces lightning as effective as strong tropical convection, occasionally exceeding the tropical storms. The frequency of heavy lightning in terms of days of occurrence is of comparable order for all regions of observations, except for the $\mathrm{N}$-Australian region where strong lightning activity happens much more frequent and on a more regular basis during monsoon build-up and break phases than in all other regions. The relatively low number for Brazil is partly due to the low number of observation days.

\subsection{Stroke characteristics and conceptual model}

Stroke peak currents can be inferred from the LINET measurements for all types of positive or negative CG or IC events. This is of special interest for the assessment of lightning $\mathrm{NO}_{\mathrm{x}}$ production as Wang et al. (1998) demonstrated that the peak current of a discharge is an appropriate scaling factor for estimates of total global NO production.

First we look at the total characteristics of positive and negative CG and IC strokes for each region separately. The stroke peak current characteristics for the different areas are shown in Fig. 28. CG and IC stroke numbers relative to the total stroke number for the respective area are shown as a function of peak current. For each region some basic statistics are given: the IC fraction $F_{I C}$ as defined before in Eq. (1) and the IC and CG ratios $\mathrm{R}$ defined as the ratio of positive and negative strokes $\mathrm{N}$ of the respective category

$\mathrm{R}_{\mathrm{IC}}=\mathrm{N}_{\mathrm{IC}+} / \mathrm{N}_{\mathrm{IC}-}$
$\mathrm{R}_{\mathrm{CG}}=\mathrm{N}_{\mathrm{CG}+} / \mathrm{N}_{\mathrm{CG}-}$

The stroke frequency distributions discussed in the following have been calculated on the basis of the "core" observational days with data collected from the inner areas of each observational region with all six stations operating. These days have been highlighted by the red dots in the respective overview plots of each region (Figs. 4, 10, 16 and 23). As demonstration of the day-to-day variability of the stroke frequency distribution "error" bars are indicated in Fig. 28 which are calculated as standard deviation of the daily distributions (percentage curves for each day). Thus they originate from samples of different size but are thought to be indicative of the storm environmental conditions prevailing on the specific days. One notes that the mid-latitudinal distributions from S-Germany exhibit the largest degree of variability whereas in the tropical regions there is much less day-today change in these conditions.

From Fig. 28 we note the dependence of the stroke numbers on peak current. All functions represent relative stroke numbers calculated with respect to the total number of $(\mathrm{CG}+\mathrm{IC})$ strokes from the respective area. Thus, given the same number of strokes for a region, the results show the percentages of strokes to be expected in a given peak current interval of $1 \mathrm{kA}$. The data from Brazil and Australia show the largest differences between the IC and CG numbers whereas for the German and Benin data the CG components contribute a larger fraction to the total stroke numbers. This behaviour is reflected by the overall (from all core data of the respective region) stroke fractions of 0.83 (Brazil), 0.82 (Australia), 0.69 (S-Germany) and 0.64 (Benin).

The distributions peak close to $3 \mathrm{kA}$, in most regions slightly below that value with the exception of the Australian strokes which peak at slightly higher values. These characteristics are found for both types of strokes, IC and CG. LINET with the chosen sensor configuration is much more 


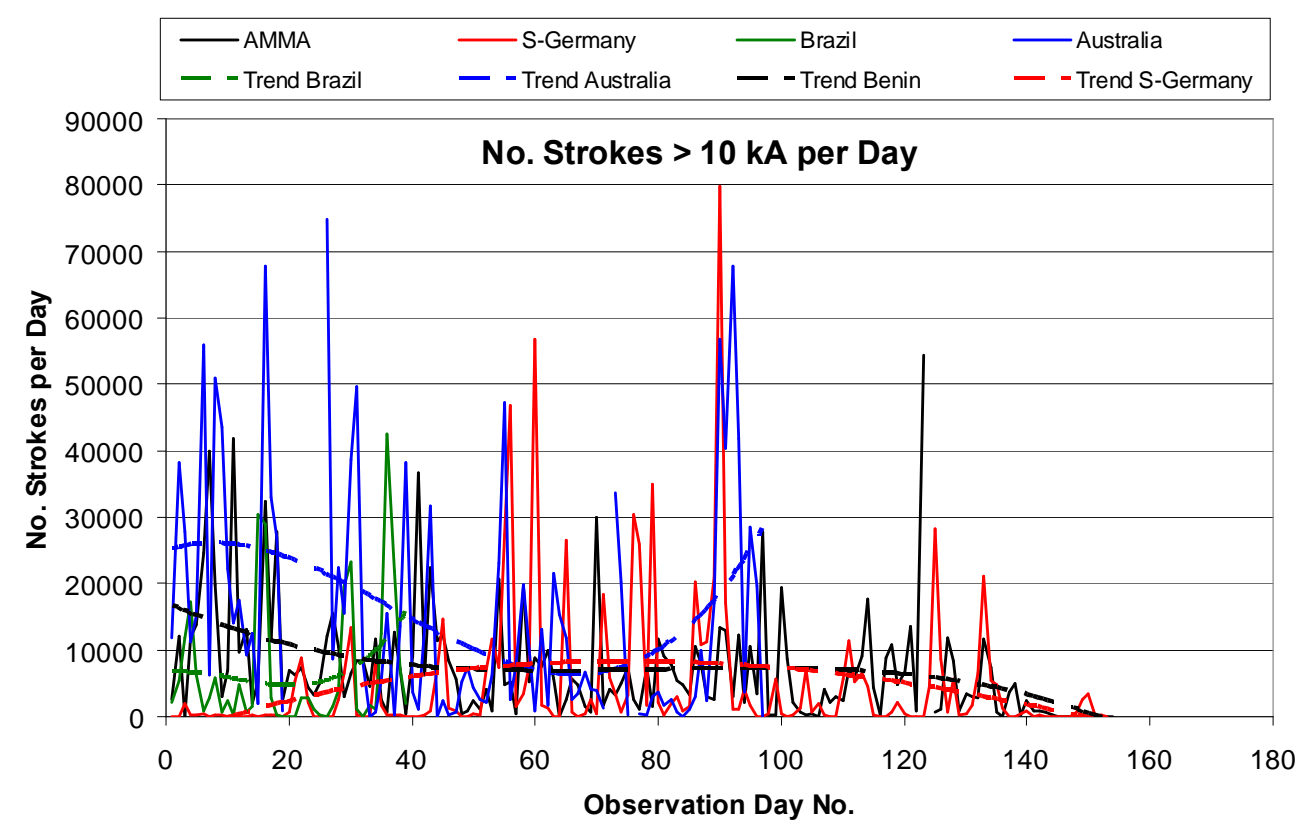

Fig. 27. Daily total stroke numbers with peak current $>10 \mathrm{kA}$ in the overall area A for the different regions of observation as a function of the number of observation days. Also shown are the 3rd order polynomial trends of the time series.
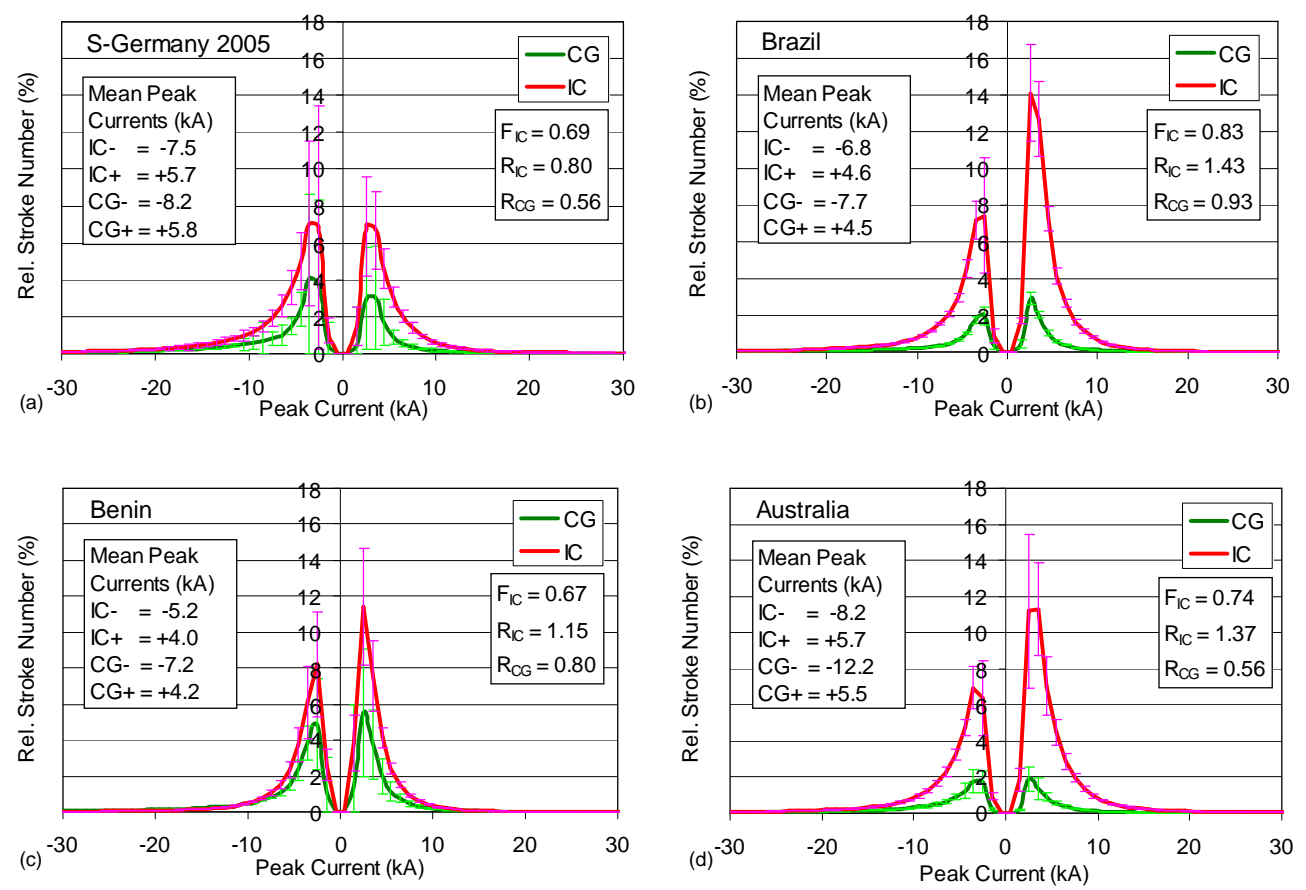

Fig. 28. Number of CG and IC strokes relative to the total number of strokes CG+IC in the respective inner observation region (I) as a function of peak current for (a) S-Germany, (b) Brazil, (c) Benin, (d) N-Australia.

efficient than most other networks. This has been referenced in many papers about LINET (e.g. Betz et al., 2007, 2009). Thus much smaller amplitude strokes can be detected as compared to other networks and, consequently, mean am- plitude values are smaller. The weak positive CG strokes are thought to represent the involvement of the lower positive charge center in the discharge process. The positive CG are relatively abundant only for weak amplitudes. Above some 

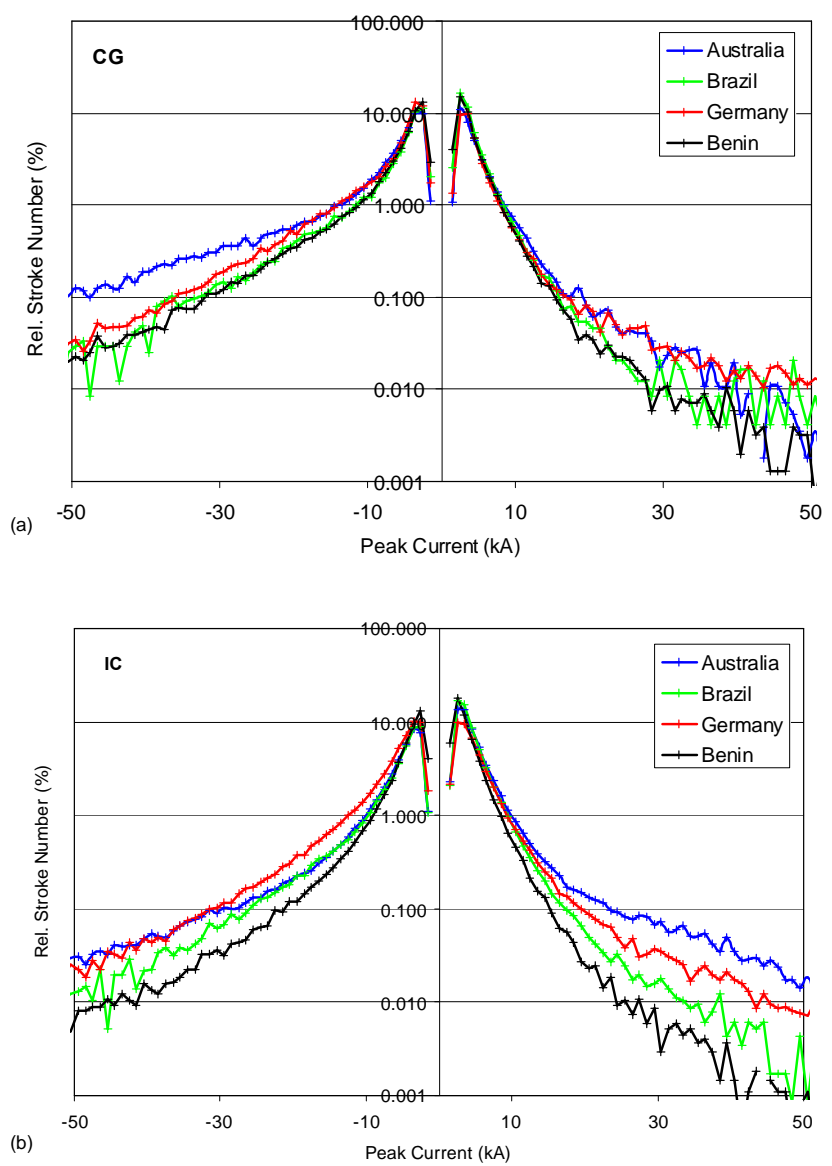

Fig. 29. Number of CG (a) and IC (b) strokes relative to the total CG and IC number, respectively, in the respective region as a function of peak current.

$15 \mathrm{kA}$ we do not find differences to other networks, provided these are sufficiently sensitive in the range 10-15 kA. This holds for all stroke types (CG-, CG+, IC-, IC+).

There is a general trend for the positive IC peak to dominate the negative one, most pronounced for Brazil and least for Germany where the peak values are similar for IC- and IC+ components. The positive IC peak tends to be associated with a more narrow IC+ distribution and a broader ICpart extending into the very negative end of the spectrum as shown more clearly in Fig. 29. The large IC+ peak leads to $\mathrm{R}_{\mathrm{IC}}$ ratios larger than one, except for the German data showing dominant negative IC- contributions from the low peak current end of the spectrum. The ground strokes do not show these characteristics, the $\mathrm{R}_{\mathrm{CG}}$ ratios are smaller than one for all regions, thus indicating the dominance of the negative CG- part over the positive one.

Mean peak currents are also indicated in Fig. 28. The strongest strokes for nearly all the different components are found in the Australian data set. Especially the strong CGare noted here while the smallest mean CG- are found for Benin. The differences in mean CG+ peak currents are less

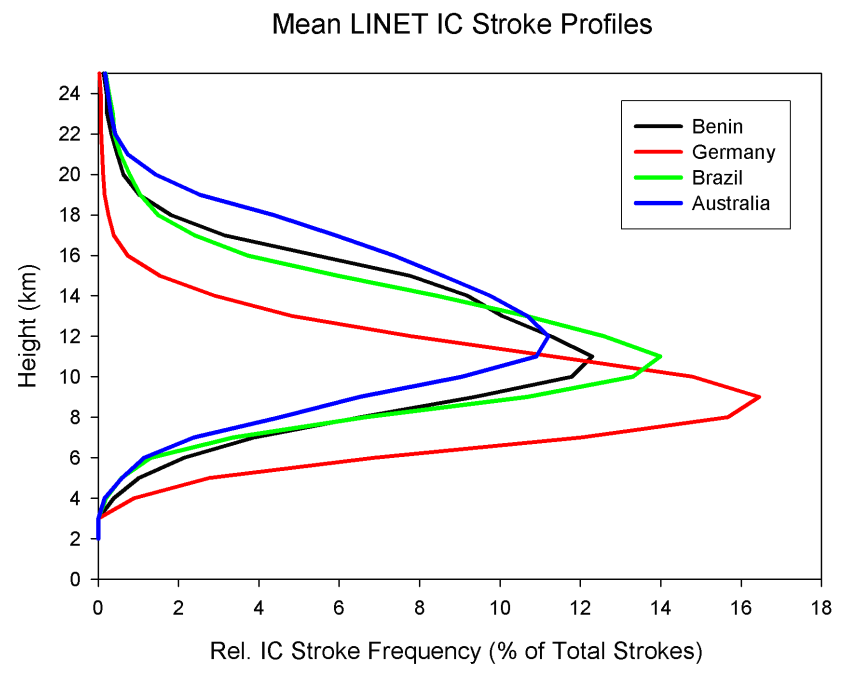

Fig. 30. Vertical profiles of the IC stroke frequencies relative to the total IC strokes observed in the respective inner area. Data base was restricted to stroke height accuracy of better than $30 \%$ on those observation days suitable for IC/CG discrimination ('core' data) as indicated in the daily overview plots for each area.

pronounced, Germany and Australia have slightly higher currents. The mean IC components from Benin are rather weak, whereas the Australian and German cloud strokes are of comparable high strength.

A comparison of the ground strokes for the different regions is presented in Fig. 29a. As just one type of strokes is compared for different regions, the total number of CG (or IC in part b) is used as a reference for normalization of the graphs. Thus the comparison indicates what percentage of all strokes of a special type can be expected to be measured in a unit peak current interval. The Australian lightning is characterized by a larger number of strong negative CG strokes compared to all other regions (in accordance with the mean values discussed above). The negative end of the spectrum dominates over the positive one which is much narrower in all regions. The positive CG+ do not show that much differences among the regions as do the negative ones. We also note the tendency of Australian lightning to produce a large fraction of strong strokes and, on the other hand, the Benin lightning to produce the lowest fraction of strong (negative and positive) strokes.

The IC characteristics are basically more symmetric than that of the CGs as shown in Fig. 29b. Again, the African lightning components are smallest over a wide range of peak currents, the positive IC part is more frequently found in the Australian lightning compared to the other regions. In a following paragraph it will be shown how these characteristics determine the $\mathrm{NO}_{\mathrm{x}}$ production.

In the general overview context of this paper we are just looking at relative stroke numbers from a large number of thunderstorm days for comparison. Thus the vertical 
Table 6. Comparison of mean IC stroke properties.

\begin{tabular}{lll}
\hline Region & $\begin{array}{l}\text { Mean IC fraction } \\
\mathrm{N}_{\mathrm{IC}} /\left(\mathrm{N}_{\mathrm{IC}}+\mathrm{N}_{\mathrm{CG}}\right)\end{array}$ & $\begin{array}{l}\text { Mean IC } \\
\text { height }(\mathrm{km})\end{array}$ \\
\hline Germany & 0.69 & 8.5 \\
Brazil & 0.83 & 11.0 \\
Benin & 0.64 & 11.1 \\
Australia & 0.82 & 12.2 \\
\hline
\end{tabular}

distributions shown in Fig. 30 reflect the stroke numbers at a given height interval relative to the total number observed in the respective inner observational area on the selected days suitable for IC/CG discrimination ("core" days). Consequently, high relative peak stroke frequencies imply a narrow vertical profile in the normalized graph as can be noted from Fig. 30. Many strokes (high maximum) at the height of the maximum imply fewer strokes at the other levels as the integral in supposed to amount to $100 \%$. The mid-latitude case from Germany has the highest relative stroke frequency and a relative narrow vertical profile with mean stroke height at $8.5 \mathrm{~km}$ (see Table 6).

Due to the higher vertical extent of convection connected to the higher tropopause height in the tropical regions we find peak frequencies at higher altitude in the tropics. The characteristics for Brazil and Benin are rather similar to each other with respect to the IC stroke profiles resulting in mean heights close to $11 \mathrm{~km}$. The Australian strokes peak a little higher up at $12.2 \mathrm{~km}$ altitude.

A summary of the mean stroke properties in the different regions is shown in Table 6. As already outlined above, the IC fraction is relatively low for the measurements in Germany and Benin, thus the highest percentage of ground strokes is found here. For the overview purposes of the present study we do not group the strokes into flashes. In principle, a ground flash may consist of multiple ground strokes either using the same channel or having different strike points at the ground, and additionally some IC strokes being part of the complete flash. We have to keep in mind this possible complexity when interpreting the numbers in Table 6. What can be inferred from Table 6 is that no simple relationship between the mean IC heights and the IC fraction exists. Regional differences of the convection seem to dominate and elevated IC strokes can be associated with both, low (W-Africa) and high (Brazil, N-Australia) IC fraction.

As discussed in the case study examples in the previous section, the errors in vertical position may be relatively large. This also implies that an overlap of the vertical distributions for positive and negative strokes is to be expected. On the other hand, when restricting the data further (see Fig. 31) to those having highest vertical accuracy (vertical error smaller than $3 \mathrm{~km}$ ) and strong amplitude (larger than $5 \mathrm{kA}$ ) some conclusions about the typical vertical charge distributions in the clouds can be drawn.
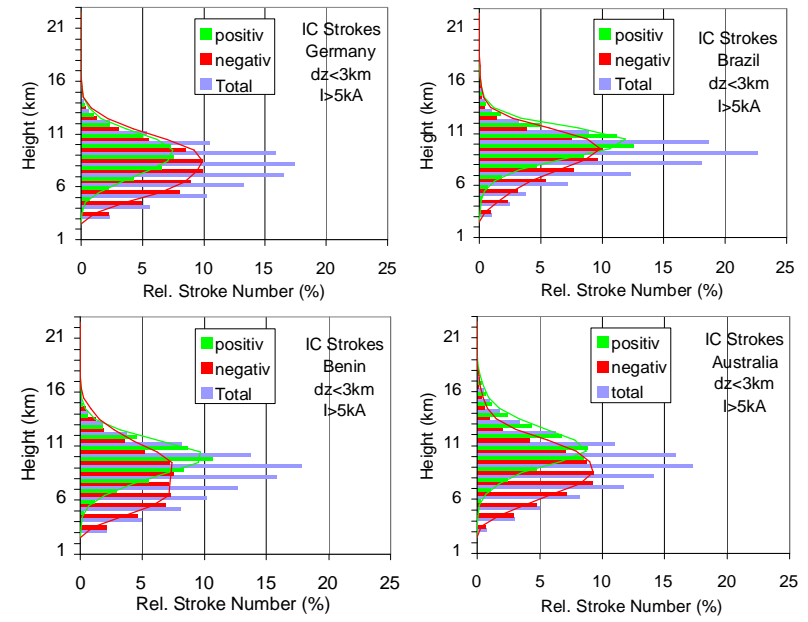

Fig. 31. Vertical profiles of the IC+ and IC- and total stroke frequencies relative to the total IC stroke number observed in the respective inner area. Data base was restricted to stroke height accuracy of better than $3 \mathrm{~km}$ and peak currents larger than $5 \mathrm{kA}$ on those observation days suitable for IC/CG discrimination ('core' data) as indicated in the daily overview plots for each area.

The general picture concluded here is based on all (selected) stroke measurements regardless of any information of individual thunderstorm development or environmental conditions prevailing on a specific day. This could introduce another source of vertical position uncertainty contributing to those positive/negative overlap structures. Nevertheless, the overall data sets from each region allow for concluding some general characteristics of the typical charge distributions as illustrated schematically in Fig. 32.

From Fig. 31 we note that the maxima of the IC+ and ICcomponents are found at different heights. The general feature is a lower negative maximum and an upper positive one. This is what would be expected from a basic tri-polar charge distribution in the thunderstorm (see e.g. Rakov and Uman, 2003) composed of a negative charge center in the middle and a lower and upper positive center. Negative strokes are supposed to transfer charge between an upper negative and a lower positive charge center whereas positive strokes are due to opposite charge configuration. We note that the separation distance of the stroke maxima is larger in Benin and Australia as compared to the German and Brazil data sets. The picture of charge distributions can be completed by the ground strokes of different polarity where negative CGs are thought to connect the negative charge center aloft with the ground and positive CGs might either involve the upper or lower positive charge center in the cloud.

The deepest convective clouds can be expected in NAustralia preferably during the build-up and break phase of the monsoon. All inferred charge centers are located relatively high up in the clouds so that the distances between the intra-cloud charge centers and those to the ground are 


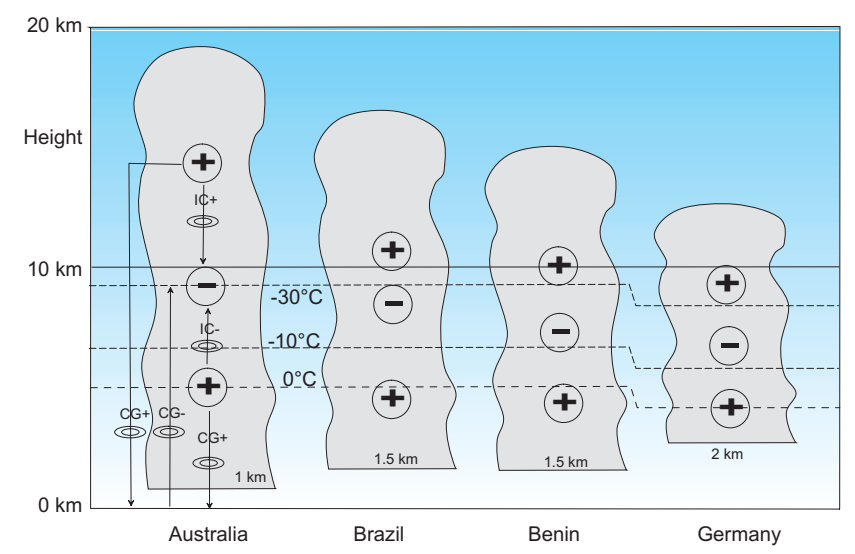

Fig. 32. Schematic view of the inferred cloud structures and charge centres for the different observation regions.

relatively large. This is in accordance with the large mean peak currents of IC and CG strokes. In Benin and Brazil we found a relatively large number of small peak current $\mathrm{CG}+$, thus indicating a somewhat lower positive charge center. Especially in Brazil many small-amplitude IC+ were found indicating small separation distances of the upper charge centers. The general picture of cloud structure can be completed by information from typical soundings (not shown here) from the different regions. These suggest a rather low cloud base close to $1 \mathrm{~km}$ height in the Darwin area due to a very humid boundary layer. The other areas are characterized by a more or less continental boundary layer with highest cloud base to be expected in S-Germany at around $2 \mathrm{~km}$ height. Brazil and Benin are in between these extremes.

\subsection{Implications for lightning $\mathrm{NO}_{\mathrm{x}}$ production}

The production of $\mathrm{NO}_{\mathrm{x}}$ by lightning has been in the focus of the field projects with LINET involvement as described in this paper. In the context of this summary we will present some implications drawn from the measurements described above. More detailed assessments of global $\mathrm{NO}_{\mathrm{x}}$ production are beyond the scope of the present summary as the aim is just to discuss the lightning measurements. A detailed description of the present state of knowledge on the assessment of $\mathrm{NO}_{\mathrm{x}}$ production from lightning can be found in Schumann and Huntrieser (2007).

For a discussion of some implications on lightning $\mathrm{NO}_{\mathrm{x}}$ production from the present measurements we make use of the findings by Wang et al. (1998) from laboratory experiments. They tried to keep the experimental conditions as close as possible to atmospheric conditions under which natural flashes occur. The sparks produced resembled natural discharges in current waveform and amplitude and were investigated under different atmospheric pressure corresponding to heights up to $8 \mathrm{~km}$. They state that NO production as a function of peak current is a useful estimator to be applied to the assessment of global $\mathrm{LNO}_{\mathrm{x}}$ production. As peak current of the strokes can be inferred from the LINET measurements the Wang et al. formulation will be used in the following for an inter-comparison of the $\mathrm{NO}_{\mathrm{x}}$ production for the different regions. The NO production per unit spark length can be written as

$n_{\mathrm{NO}}(I)=\mathrm{a}+\mathrm{b} \cdot \mathrm{I}+\mathrm{c} \cdot \mathrm{I}^{2}$

where $\mathrm{n}_{\mathrm{NO}}$ is the number of $\mathrm{NO}$ molecules produced per

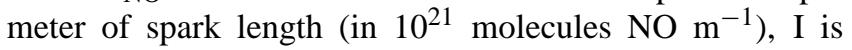
peak current amplitude in $\mathrm{kA}$, and $\mathrm{a}, \mathrm{b}$, and $\mathrm{c}$ are constants $(a=0.14, b=0.026, c=0.0025)$. For the following calculations we assume that the range of applicability of Eq. (6) can be extended outside the range $(6<\mathrm{I}<30 \mathrm{kA})$ originally tested by Wang et al. (1998) in order to cover also smaller and larger values measured. We think that we can extrapolate the quadratic dependence claimed by Wang et al. (1998) because our peak current data show quite rapidly decreasing number frequencies towards larger amplitudes which would limit any errors due to this uncertainty.

By using Eq. (6) we can directly compute the stroke relative NO production rates from the distributions of the stroke numbers shown in Fig. 28. As a reference for normalization the total stroke numbers $\mathrm{N}_{\mathrm{CG}}+\mathrm{N}_{\mathrm{IC}}$ observed in each region are used for the comparison shown in Fig. 33. Therefore, we can compare the relative importance of CG and IC strokes in the different regions. For demonstrating the net effect, the integrated values (from $-400 \mathrm{kA}$ up to the actual peak current) of NO production are shown additionally. The rate of change (increase) of the accumulated graphs does demonstrate the contribution from the respective categories. Moreover, we directly see the contributions from the overall negative and positive stroke population by comparing the values from the accumulated curves at zero and $+200 \mathrm{kA}$ peak power, the latter also representing total $\mathrm{NO}$ accumulation from all strokes (contributions from rare larger amplitude strokes not changing this result substantially).

As the present data set does not represent a complete convective season in each of the regions (e.g. the Brazilian data just cover one month) we cannot compare absolute lightning frequencies in this paper. Thus we do not relate the numbers for $\mathrm{NO}_{\mathrm{x}}$ production to a "global" data set of all measurements lumped together. Instead, we can compare the NO yield from a stroke sample of equal number (say 100 strokes from each region) and unit length for each of the regions. The samples differ in their peak current distribution and in the mean IC height observed for each region. Thus we want to study the effects of different current distributions and different IC and CG contributions on NO production, well knowing that the effects of channel length and regional thunderstorm occurrence etc. remain unresolved here.

As the basis for the computation of NO production is the normalized amplitude distribution (in \%) for each region separately (providing the number of strokes per amplitude interval of $1 \mathrm{kA}$ relative to the total stroke number of the 

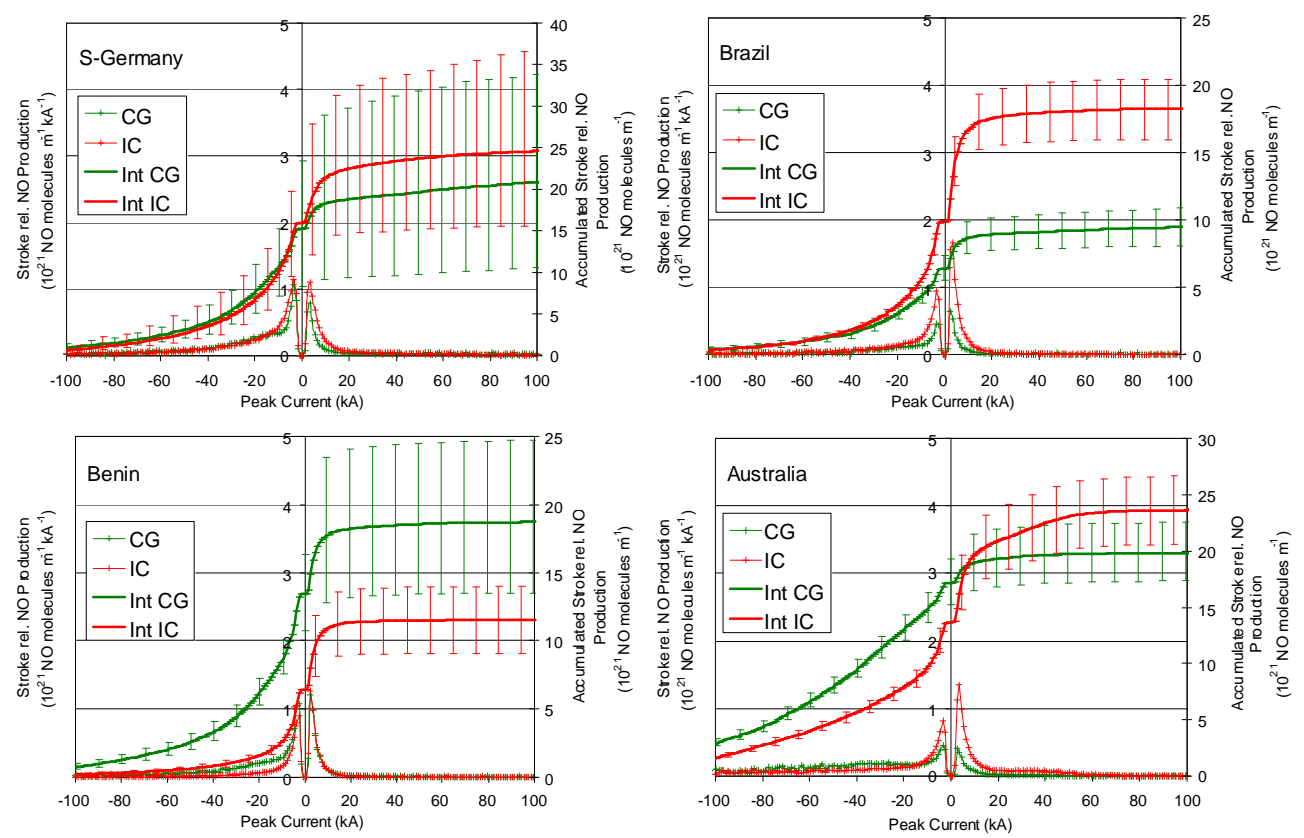

Fig. 33. Stroke relative NO production according to Eq. (6) and accumulated (integral) values for the different experimental areas as a function of peak current. Error bars represent variability due to daily changes in stroke distributions shown in Fig. 28.

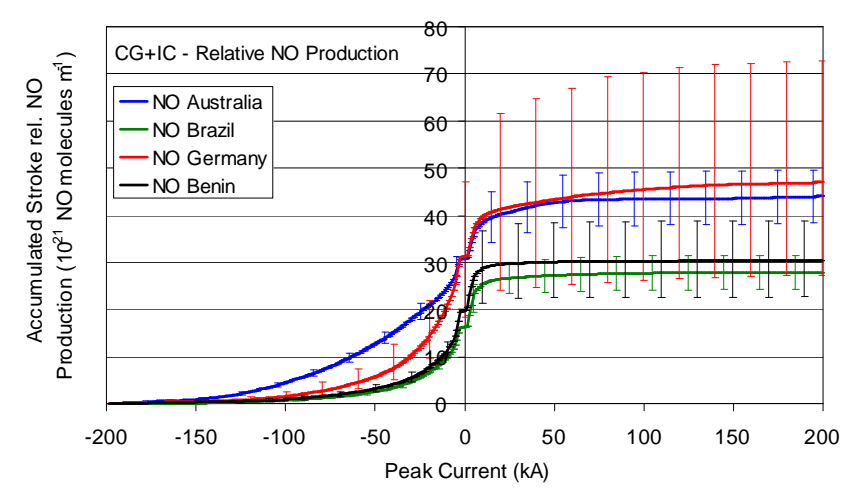

Fig. 34. Accumulated (integral) stroke relative NO production for the different regions including the CG and IC contributions. Error bars represent variability due to daily changes in stroke distributions shown in Fig. 28.

representative sample of the core data) we compute the NO yield per meter and kA interval of 100 strokes by multiplying by the Wang formula. Integrating this over all amplitudes provides the total NO production per meter from 100 strokes for each region, thus some kind of efficiency of the lightning activity for NO production resulting from differences in stroke amplitudes and types (heights). These values from the different regions can be compared directly.

The effect of the day-to-day variations of the stroke distributions as indicated in Fig. 28 is also demonstrated in Fig. 33 by the vertical "error" bars which also indicate for the integral graphs an error accumulation with increasing peak cur- rent. The "error bars" were introduced as the integration of the upper and lower bounds defined by the corresponding "error" curves given in the distribution functions. The German and Benin data show the largest variability whereas the Australian and Brazilian data produce much less scatter. These results also give an indication on the sensitivity of assessments of global $\mathrm{NO}_{\mathrm{x}}$ production which are based on measurements from one specific observation day where airborne observations were performed during a field experiment.

Besides the dependence on peak current, NO production also depends on air density. According to Wang et al. (1998) the amount of NO produced reduces with decreasing atmospheric pressure. Compared to the conditions close to the ground (say $2.5 \mathrm{~km}$ mean altitude for a $\mathrm{CG}$ ), a rough estimate from these results gives a factor of 2.2 less NO production at $12.2 \mathrm{~km}$ (mean stroke heights for Australia), a factor of 2.0 less at around $11 \mathrm{~km}$ for Brazil and Benin and a factor of 1.6 less at $8.5 \mathrm{~km}$ in Germany for a spark of the same magnitude. Thus, roughly speaking, the density effect alone makes ground flashes up to twice as efficient NO-producers than their intra-cloud counterparts of the same strength. These effects have also been taken into account in Fig. 33.

Regarding the German strokes we find relative large similarities between the CG and IC components leading to rather similar magnitudes of the NO production and the integrals for both components. The negative CG- and IC- strokes produce about the same amount of NO. In total, the contribution of the positive strokes to the overall NO production is smaller than that of the negative strokes. Among the positive strokes 
the IC contribution is dominant thus leading to a slightly larger total NO production from IC strokes as compared to CG strokes.

In Brazil the negative amplitude CG- and IC- contribute not too different amounts to the NO production as is even more clearly the case for the German data. For the positive part of the strokes we note the dominance of the IC+ over the $\mathrm{CG}+$ part resulting in a distinct IC surplus of NO production.

In contrast to this we find a CG- dominance over the ICcontributions in the African and Australian data. This is mainly due to the relatively large number of CG- observed here. For Benin the negative IC- play a minor role for the NO from the total negative amplitude strokes while for Australia their contribution is more significant. In Benin there is basically no difference in the contributions from the positive components whereas in Australia we find a dominance of the $\mathrm{IC}+$ over the CG+ contributions leading to a slight surplus of the total amounts of NO contributed by IC strokes over that of the CGs. The latter tendency is not found for Benin where in total the CG contributions are dominant.

Figure 34 summarizes the results obtained above for the CG and IC components into an overall stroke relative NO production. We note that about $2 / 3$ of the final NO production is due to negative strokes. As the positive spectra tend to be more narrow than the negative ones, we note a sharp increase of the integrals at small positive peak currents (as was also the case for the small negative currents) followed by a much less pronounced increase at larger positive currents. For Brazil and Benin there is even a hold up of further increase in production rate due to the very small number of positive strokes of large amplitude. The largest overall NO production rates are found for Germany and N-Australia at the end of integration. It is the effect of the IC emission height (air density) which lead to this relatively close final result as the German emissions happen at the lowest altitudes and the Australian ones at the highest altitudes as found from the present results. Also the NO production for Brazil and Benin are very close to each other and result in a much smaller total production as compared to the German and Australian values. Except for the high daily variability in the German data, this trend seems to be representative for any arbitrarily selected days as indicated by the error bars for the tropical regions.

We note that the relative numbers discussed in this paper allow for a comparison of the lightning characteristics in the different regions under the same conditions but do not yet give the complete picture of the absolute NO production rates. The actual NO production depends not only on the stroke numbers, peak current or air density but also on the lightning channel length, diameter or the phase of the discharge. Channel length or diameter cannot be inferred directly from the present measurements. The role of the different phases of a flash in lightning $\mathrm{NO}_{\mathrm{x}}$ production is still far from being well understood. Thus for the purpose of the present study we did confined ourselves to a comparison of the lightning characteristics in the different regions relative to each other.

\section{Summary and conclusions}

The present paper presents an overview of the lightning measurements obtained by the novel VLF lightning detection network LINET which have been performed recently in various parts of the world. The system has been deployed in the framework of different field campaigns with emphasize on lightning $\mathrm{NO}_{\mathrm{x}}$ production. Besides the measurements performed in S-Germany the focus was on tropical lightning. We have presented here a summary of the main results from each region and a comparison of some characteristic features especially with respect to lightning $\mathrm{NO}_{\mathrm{x}}$ production.

The regional and temporal distributions of lightning were found to vary according to short range fluctuations of the order of a few days and to long term seasonal variability. This was basically reflecting the monsoonal activity in NorthAustralia and West-Africa accompanied by the southward (northward) progression of the monsoon trough and subsequent retreat towards the equator. During build-up and break periods convection and lightning was most intense while especially the Australian active monsoon phase was characterized by a distinct lightning minimum due to the maritime conditions. Even though the measurements in Brazil did only cover slightly more than one month of convective season the basic variability connected to the SACZ was well captured by high activity in the tropical air masses changing to low activity in the drier air masses from the south. The mid-latitude build-up and retreat of summer convection in southern Germany was also well captured by the lightning activity peaking in July. The regional distribution of lightning was found to follow some well known convective initiation mechanisms like terrain induced orographic forcing (especially for Germany and Brazil), land-sea breeze circulations (especially in Australia) or the influence of major metropolitan areas (like São Paulo).

The analysis of extreme cases showed that the heaviest storms in terms of stroke numbers per day were found in Germany and in Australia, while regional lightning was somewhat less pronounced in Brazil and W-Africa. The frequency of extreme days was by far largest in N-Australia due to the heavy storms during monsoon build-up and break periods.

One of the characteristics of LINET is that it can discriminate between ground and cloud strokes and provide information of the emission height of a VLF radiation source even though the complete lightning channel cannot be resolved in detail. We could demonstrate that there are characteristic differences in emission height from the mid-latitudes to the tropics. Maximum IC stroke rates varied from 8 (SGermany) to about $12 \mathrm{~km}$ height (Australia). On average, the Brazilian and Benin data had some kind of intermediate properties. The IC-fractions were found to be rather high in 
Brazil and Australia whereas the German and Benin data indicate that ground strokes play a larger role in these areas.

The distribution of the strokes along peak current shows some similarities for the different regions. There is a general trend for the positive IC peak to be the dominant one, most pronounced for Brazil and least pronounced for Germany. In connection to this, the IC+ current distribution is somewhat narrower than the IC- current distribution. This broader negative distribution is even more pronounced in the case of CG strokes. This leads to the large number of negative CG strokes at large negative peak currents, a feature especially important for the $\mathrm{NO}_{\mathrm{x}}$ production arising from it. In accordance with this broadening, all regions are characterized by a dominance of the negative ground stroke numbers over the positive ones except for amplitudes larger than around $100 \mathrm{kA}$ in the German cases.

Based on the Wang et al. (1998) model of $\mathrm{NO}_{\mathrm{x}}$ production from sparks a comparison of the $\mathrm{NO}_{\mathrm{x}}$ production efficiency of lightning was performed for the different regions under investigation. Comparing the NO production from a unit stroke length and taking into account the different emission heights for IC and CG strokes it turned out that the total $\mathrm{LNO}_{\mathrm{x}}$ production was most efficient for the $\mathrm{N}$-Australian thunderstorms closely followed by the S-German lightning. The Brazil and Benin lightning was found to behave very similar to each other in terms of total specific $\mathrm{LNO}_{\mathrm{x}}$ production which was found nearly a factor of two less efficient. Looking at the contributions from IC and CG strokes the conclusions were different from those for the total contributions: even though the Brazil and Benin strokes produced nearly the same total NO amount, the major contribution in Brazil was from IC strokes whereas in Benin it was due to the CG strokes. Thus a similar total amount was not a result of similar lightning characteristics but rather resulted by chance. For the German and Australian data the CG and IC contributions to total $\mathrm{NO}$ production were of the same order.

As it was the aim of the present study to present an overview of the LINET measurements performed on different continents we confined ourselves to a comparison of the stroke properties and some implications with regard to lightning $\mathrm{NO}_{\mathrm{x}}$ production. This comparison was performed in a relative sense. To conclude absolute numbers of $\mathrm{NO}_{\mathrm{x}}$ production from the lightning measurements alone is not possible in a direct approach as NO production from a flash depends on properties which cannot be provided by the LINET measurements alone. Among these are the geometry of a flash including length and diameter of the channel or the detection of different components responsible for NO production, the significance of which are not known very well. On the other hand, the work of Wang et al. (1998) suggests that stroke peak current might be a good indicator for lightning NO production. Thus we think that the results obtained by using the Wang results have some significance for NO production from storms within the regimes investigated in the present study. Anyway, interpreting the lightning data in a relative sense as followed here can be expected to provide meaningful results of regime comparison in terms of lightning characteristics and, moreover, also in terms of NO production rates as far as stroke intensity is concerned.

An extended approach for concluding absolute $\mathrm{LNO}_{\mathrm{x}}$ production rates by making use of LINET measurements was followed by Huntrieser et al. (2008) for storms observed during TROCCINOX in Brazil and some cases from Germany. The lightning data were related to airborne $\mathrm{NO}_{\mathrm{x}}$ measurements thus serving as a scaling parameter for $\mathrm{LNO}_{\mathrm{x}}$ production. Using Wang et al. production rates (as applied in the present study) and best estimates of other necessary parameters, like transport properties of $\mathrm{NO}_{\mathrm{x}}$ within the cloud into the anvil where the measurements were performed, scaling factors (effective stroke length) could be derived for relating LINET-observed peak currents to $\mathrm{LNO}_{\mathrm{x}}$ measured in the anvil. From this study it was found that the effective lengths needed to explain anvil $\mathrm{LNO}_{\mathrm{x}}$ were in the order of a few tens of kilometers. The effective stroke length was found to be the dominant factor for $\mathrm{LNO}_{\mathrm{x}}$ production, stroke peak current or emission height were less significant parameters. Thus the results of the present study are setting the base for further investigations of $\mathrm{LNO}_{\mathrm{x}}$ production especially in other regions (N-Australia and W-Africa) than studied up to now.

For the purpose of the present paper we followed simply a regional classification of lightning regimes. Thus, in order to compare characteristics of the different regions, we do not go into details of different air masses as has been done by Huntrieser et al. (2008) for some selected case studies especially relating to the airborne measurements performed during the different campaigns. So our present results represent regional characteristics including a mixture of different convective conditions and storm types. The degree of dayto-day variability has been shown to be relatively large in the German area whereas in the tropical regions investigated we found less variations. On the other hand, the statistics obtained for the total areas or times are dominated by the most significant events which might be happening only during a few days and thus are typical for the prevailing conditions on these days. A more detailed look at these air mass or storm characteristics has to be left to future work.

Acknowledgements. TROCCINOX was partially funded by the Commission of the European Community under the contract EVK2-CT-2001-00122. TROCCINOX was performed as a coordinated action of European and Brazilian research institutes and agencies together with the Brazilian project Tropical Convection and Cirrus Experiment Brazil (TroCCiBras). The LINET system was installed in Brazil as a joint effort between DLR and the IPMet/UNESP (Instituto de Pesquisas Meteorológicas/Universidade Estadual Paulista). Special thanks is due to the IPMet technical team B. Biazon and M. Leite and to T. Fehr (now at ESA) for system installation and operation. In support of the European Commission funded SCOUT-O3 tropical campaign and the Tropical Warm Pool - International Cloud Experiment TWP-ICE the LINET system was installed in the Darwin area (N-Australia) as a 
joint effort between DLR and the Bureau of Meteorology Research Center (BMRC) which is now part of the Centre for Australian Weather and Climate Research (CAWCR) and by support from the US DOE-ARM (Department of Energy-Atmospheric Radiation Measurement Program) for TWP-ICE. The authors acknowledge B. Atkinson and A. Noonan (BOM) for making possible the system operations. Based on a French initiative, AMMA was built by an international scientific group and is currently funded by a large number of agencies, especially from France, UK, US and Africa. It has been the beneficiary of a major financial contribution from the European Community's Sixth Framework Research Programme. We specially thank the IRD (L'Institut de recherché pour le développement) AOC (AMMA operation Center) staff in Cotonou for logistics help and E. Lezinme (University Abomey Calavi UAC) for valuable assistance in system installation and operation during sometimes adventurous conditions. The data analysis was also supported in the framework of the HGF COSI-TRACKS (Convective Storms Virtual Institute-Transport and Chemical Conversion in Convective Systems) as well as the BMBF funded RegioExAKT (Regional Risk of Convective Extreme Weather Events: User-oriented Concepts for Trend Assessment and Adaptation) projects. The technical and logistical assistance of L. Oswald (DLR) with the operations in Darwin and S-Germany is greatly appreciated. Finally we greatly appreciate careful proofreading of the manuscript and many helpful comments from the coordinator of the TROCCINOX project U. Schumann as well as H. Huntrieser (DLR).

Edited by: C. Reeves

\section{References}

Allen, G., Vaughan, G., Bower, K. N., et al.: Aerosol and tracegas measurements in the Darwin area during the wet season, J. Geophys. Res., 113, D06306, doi:10.1029/2007JD008706, 2008.

Betz, H.-D., Schmidt, K., Oettinger, W. P., and Wirz, M.: Lightning Detection with 3D Discrimination of Intracloud and Cloud-to-Ground Discharges, Geophys. Res. Lett., 31, L11108, doi:10.1029/2004GL019821, 2004.

Betz, H.-D., Schmidt, K., Fuchs, B., Oettinger, W. P., and Höller, H.: Cloud Lightning: Detection and Utilization for Total Lightning Measured in the VLF/LF Regime, J. Light. Res., 2, 1-17, 2007.

Betz, H.-D., Marshall, T. C., Stolzenburg, M., Schmidt, K., Oettinger, W. P., Defer, E., Konarski, J., Laroche, P., and Dombai, F.: Detection of in-cloud lightning with VLF/LF and VHF networks for studies of the initial discharge phase, Geophys. Res. Lett., 35, L23802, doi:10.1029/2008GL035820, 2008.

Betz, H.-D., Schmidt, K., Laroche, P., Blanchet, P., Oettinger, W. P., Defer, E., Dziewit, Z., and Konarski, J.: LINET - An international lightning detection network in Europe, Atmos. Res., 91, 564-573, doi:10.1016/j.atmosres.2008.06.012, 2009.

Brunner, D., Siegmund, P., May, P. T., Chappel, L., Schiller, C., Müller, R., Peter, T., Fueglistaler, S., MacKenzie, A. R., Fix, A., Schlager, H., Allen, G., Fjaeraa, A. M., Streibel, M., and Harris, N. R. P.: The SCOUT-O3 Darwin Aircraft Campaign: rationale and meteorology, Atmos. Chem. Phys., 9, 93-117, 2009, http://www.atmos-chem-phys.net/9/93/2009/.
Carey, L. D. and Rutledge, S. A.: The Relationship between Precipitation and Lightning in Tropical Island Convection: A C-Band Polarimetric Radar Study, Mon. Weather Rev., 128, 2687-2710, 2000.

Christian, H. J., Blakeslee, R. J., Boccippio, D. J., Boeck, W. L., Buechler, D. E., Driscoll, K. T., Goodman, S. J., Hall, J. M., Koshak, W. J., Mach, D. M., and Stewart, M. F.: Global frequency and distribution of lightning as observed from space by the Optical Transient Detector, J. Geophys. Res., 108(D1), 4005, doi:10.1029/2002JD002347, 2003.

Crutzen, P. J.: The influence of nitrogen oxides on the atmospheric ozone content, Q. J. Roy. Meteor. Soc., 96, 320-327, 1970.

Carvalho, L. M. V., Jones, C., and Liebmann, B.: The South Atlantic Convergence Zone: Intensity, Form, Persistence, and Relationships with Intraseasonal to Interannual Activity and Extreme Rainfall, J. Climate, 17, 88-108, 2004.

Dye, J. E., Ridley, B. A., Skamarock, W., Barth, M., Venticinque, M., Defer, E., Blanchet, P., Thery, C., Laroche, P., Baumann, K., Hubler, G., Parrish, D. D., Ryerson, T., Trainer, M., Frost, G., Holloway, J. S., Matejka, T., Bartels, D., Fehsenfeld, F. C., Tuck, A., Rutledge, S. A., Lang, T., Stith, J., and Zerr, R.: An overview of the Stratospheric-Tropospheric Experiment - Radiation, Aerosols, and Ozone (STERAO)-Deep Convection experiment with results for the July 10, 1996 storm, J. Geophys. Res., 105(D8), 10023-10045, 2000.

Finke, U. and Hauf, T.: The characteristics of lightning ocurrence in southern Germany, Contrib. Atmos. Phys., 69, 361-374, 1996.

Frederick, K. and Schumacher, C.: Anvil Characteristics as Seen by C-POL during the Tropical Warm Pool International Cloud Experiment (TWP-ICE), Mon. Weather Rev., 136, 206-222, 2008.

Hagen, M., Bartenschlager, B., and Finke, U.: Motion characteristics of thunderstorms in southern Germany, Meteorol. Appl. 6, 227-239, 1999.

Höller, H., Finke, U., Huntrieser, H., Hagen, M., and Feigl, C.: Lightning produced $\mathrm{NO}_{\mathrm{x}}(\mathrm{LINOX})$ - Experimental design and case study results, J. Geophys. Res., 104(D11), 13911-13922, 1999.

Höller, H. and Schumann, U.: EULINOX - The European Lightning Nitrogen Oxides Project, Deutsches Zentrum für Luft- und Raumfahrt, Köln, Germany, 240 pp., DLR-FB 2000-28, 2000.

Huntrieser, H., Schlager, H., Feigl, C., and Höller, H.: Transport and production of $\mathrm{NO}_{\mathrm{x}}$ in electrified thunderstorms: Survey of previous studies and new observations at midlatitudes, J. Geophys. Res., 103, 28247-28264, 1998.

Huntrieser, H., Feigl, C., Schlager, H., Schröder, F., Gerbig, C., van Velthoven, P., Flatøy, F., Théry, C., Petzold, A., Höller, $\mathrm{H}$., and Schumann, U.: Airborne measurements of $\mathrm{NO}_{\mathrm{x}}$, tracer species, and small particles during the European Lightning Nitrogen Oxides Experiment, J. Geophys. Res., 107(D11), 4113, doi:10.1029/2000JD000209, 2002.

Huntrieser, H., Schumann, U., Schlager, H., Höller, H., Giez, A., Betz, H.-D., Brunner, D., Forster, C., Pinto Jr., O., and Calheiros, R.: Lightning activity in Brazilian thunderstorms during TROCCINOX: implications for $\mathrm{NO}_{\mathrm{x}}$ production, Atmos. Chem. Phys., 8, 921-953, 2008,

Janicot, S., Thorncroft, C. D., Ali, A., Asencio, N., Berry, G., Bock, O., Bourles, B., Caniaux, G., Chauvin, F., Deme, A., Kergoat, L., Lafore, J.-P., Lavaysse, C., Lebel, T., Marticorena, B., Mounier, F., Nedelec, P., Redelsperger, J.-L., Ravegnani, F., Reeves, C. 
E., Roca, R., de Rosnay, P., Schlager, H., Sultan, B., Tomasini, M., Ulanovsky, A., and ACMAD forecasters team: Large-scale overview of the summer monsoon over West Africa during the AMMA field experiment in 2006, Ann. Geophys., 26, 25692595, 2008,

http://www.ann-geophys.net/26/2569/2008/.

Jones, C. and Carvalho, L. M. V.: Active and Break Phases in the South American Monsoon System, J. Climate, 15, 905-914, 2002.

Kaltenböck, R.: The outbreak of severe storms along convergence lines northeast of the Alps, Case study of the 3 August 2001 mesoscale convective system with a pronounced bow echo, Atmos. Res., 70, 55-75, 2004.

Keenan, T. D. and Carbone, R. E.: A preliminary morphology of precipitation systems in tropical northern Australia, Q. J. Roy. Meteor. Soc., 118, 283-326, 1992.

Keenan, T. D., Rutledge, S., Carbone, R., Wilson, J., Takahashi, T., May, P., Tapper, N., Platt, M., Hacker, J., Sekelsky, S., Moncrieff, M., Saito, K., Holland, G., Crook, A., and Gage, K.: The Maritime Continent Thunderstorm Experiment (MCTEX): Overview and Some Results, B. Am. Meteorol. Soc., 81, 2433-2455, 2000.

Koike, M., Kondo, Y., Kita, K., Takegawa, N., Nishi, N., Kashihara, T., Kawakami, S., Kudoh, S., Blake, D., Shirai, T., Liley, B., Ko, M., Miyazaki, Y., and Kawasaki, Z.: Measurements of reactive nitrogen produced by tropical thunderstorms during BIBLE-C, J. Geophys. Res., 112, D18304, doi:10.1029/2006JD008193, 2007.

Krehbiel, P. R., Riousset, J. A., Pasko, V. P., Thomas, R. J., Rison, W., Stanley, M. A., and Edens, H. E.: Upward electrical discharges from thunderstorms, Nature Geosci., 1, 233-237, 2008.

Kuleshov, Y., de Hoedt, G., Wright, W., and Brewster, A.: Thunderstorm distribution and frequency in Australia, Aust. Meteorol. Mag., 51, 145-154, 2002.

Kuleshov, Y., Mackerras, D., and Darveniza, M.: Spatial distribution and frequency of lightning activity and lightning flash density maps for Australia, J. Geophys. Res., 111, D19105, doi:10.1029/2005JD006982, 2006.

Lawrence, M. G., Chameides, W. L., Kasibhatla, P. S., Levy II, H., and Moxim, W.: Lightning and atmospheric chemistry: The rate of atmospheric NO production, in: Handbook of Atmospheric Electrodynamics, edited by: Volland, H., 189-202, CRC Press, Boca Raton, Florida, USA, 1995.

Liebmann, B., Kiladis, G. N., Marengo, J. A., Ambrizzi, T., and Glick, J. D.: Submonthly Convective Variability over South America and the South Atlantic Convergence Zone, J. Climate, 12, 1877-1891, 1999.

Mach, D. M., Christian, H. J., Blakeslee, R. J., Boccipio, D. J., Goodman, S. J., and Boeck, W. L.: Performance assessment of the Optical Transient Detector and Lightning Imaging Sensor, J. Geophys. Res., 112, D09210, doi:10.1029/2006JD007787, 2007.

May, P. T. and Ballinger, A.: The Statistical Characteristics of Convective Cells in a Monsoon Regime (Darwin, Northern Australia), Mon. Weather Rev., 135, 82-92, 2007.

May, P. T., Mather, J. H., Vaughan, G., and Jakob, C.: Field Research: Characterizing Oceanic Convective Cloud Systems, The Tropical Warm Pool International Cloud Experiment, B. Am. Meteorol. Soc., 89, 153-155, 2008a.
May, P. T., Mather, J. H., Vaughan, G., Jakob, C., McFarquhar, G. M., Bower, K. N., and Mace, G. G.: The Tropical Warm Pool International Cloud Experiment, B. Am. Meteorol. Soc., 89, 629645, 2008b.

Naccarato, K. P., Pinto Jr., O., and Pinto, I. R. C. A.: Evidence of thermal and aerosol effects on the cloud-to-ground lightning density and polarity over large urban areas of Southeastern Brazil, Geophys. Res. Lett., 30(13), 1674, doi:10.1029/2003GL017496, 2003.

Pasko, V. P., Stanley, M. A., Matthews, J. D., Inan, U. S., and Wood, T. G.: Electrical discharge from a thundercloud top to the lower ionosphere, Nature, 416, 152-154, 2002.

Pinto Jr., O., Pinto, I. R. C. A., and Naccarato, K. P.: Maximum cloud-to-ground lightning flash densities observed by lightning location systems in the tropical region: A review, Atmos. Res., 84, 189-200, 2007.

Rakov, V. A. and Uman, M. A.: Lightning - Physics and Effects, Cambridge University Press, 687 pp., 2003.

Redelsperger, J.-L., Thorncroft, C. D., Diedhiou, A., Lebel, T., Parker, D. J., and Polcher. J.: African Monsoon Multidisciplinary Analysis: An International Research Project and Field Campaign, B. Am. Meteorol. Soc., 87, 1739-1746, 2006.

Rutledge, S. A., Williams, E. R., and Keenan, T. D.: The Down Upper Doppler and Electricity Experiment (DUNDEE): Overview and Preliminary Results, B. Am. Meteorol. Soc., 73, 3-16, 1992.

Schulz, W., Cummins, K., Diendorfer, G., and Dorninger, M.: Cloud-to-ground lightning in Austria: A 10-year study using data from a lightning location system, J. Geophys. Res., 110, D09101, doi:10.1029/2004JD005332, 2005.

Schumann, U. and Huntrieser, H.: The global lightning-induced nitrogen oxides source, Atmos. Chem. Phys., 7, 3823-3907, 2007, http://www.atmos-chem-phys.net/7/3823/2007/.

Schmidt, K.: Ortung und Analyse von Blitzentladungen mittels Registrierung von VLFAtmospherics innerhalb eines Messnetzes, Dissertation Ludwig-Maximilians University of Munich, Germany, 129 pp., 2007.

Shao, X.-M., Stanley, M., Regan, A., Harlin, J., Pongratz, M., and Stock, M.: Total Lightning Observations with the New and Improved Los Alamos Sferic Array (LASA), J. Atmos. Ocean. Tech., 23, 1273-1288, 2006.

Vaughan, G., Schiller, C., MacKenzie, A. R., Bower, K., Peter, T., Schlager, H., Harris, N. R. P., and May, P. T.: SCOUTO3/ACTIVE: High-altitude Aircraft Measurements around Deep Tropical Convection, B. Am. Meteorol. Soc., 89, 647-662, 2008.

Vollmert, P., Fink, A. H., and Besler, H.: Ghana dry zone und Dahomey gap: Ursachen für eine Niederschlagsanomalie im tropischen Westafrika, Die Erde, 134, 375-393, 2003.

Wang, Y., DeSilva, A. W., and Goldenbaum, G. C.: Nitric oxide production by simulated lightning: Dependence on current, energy, and pressure, J. Geophys. Res., 103, 19149-19159, 1998.

Williams, E. R., Rutledge, S. A., Geotis, S. G., Renno, N., Rasmussen, E., and Rickenbach, T.: A Radar and Electrical Study of Tropical "Hot Towers", J. Atmos. Sci., 49, 1386-1395, 1992.

WMO (World Meteorological Organization): Scientific assessment of ozone depletion: 1994, Rep. 37, Global Ozone Res. and Monit. Proj., Geneva, 1995. 